This item was submitted to Loughborough's Research Repository by the author.

Items in Figshare are protected by copyright, with all rights reserved, unless otherwise indicated.

\title{
Stock returns forecasting with metals: Sentiment vs. fundamentals
}

PLEASE CITE THE PUBLISHED VERSION

http://dx.doi.org/10.1080/1351847X.2017.1323770

PUBLISHER

(C) Taylor \& Francis (Routledge)

VERSION

AM (Accepted Manuscript)

PUBLISHER STATEMENT

This work is made available according to the conditions of the Creative Commons Attribution-NonCommercialNoDerivatives 4.0 International (CC BY-NC-ND 4.0) licence. Full details of this licence are available at: https://creativecommons.org/licenses/by-nc-nd/4.0/

\section{LICENCE}

CC BY-NC-ND 4.0

\section{REPOSITORY RECORD}

Jordan, Steven J., Andrew Vivian, and Mark Wohar. 2019. "Stock Returns Forecasting with Metals: Sentiment Vs. Fundamentals". figshare. https://hdl.handle.net/2134/24795. 


\title{
Stock Returns Forecasting with Metals: Sentiment vs. Fundamentals*
}

\author{
Steven J. Jordan \\ Alfaisal University \\ sjordan@alfaisal.edu \\ Andrew Vivian (corresponding author) \\ School of Business and Economics \\ Loughborough University \\ a.j.vivian@lboro.ac.uk \\ Mark E. Wohar \\ University of Nebraska-Omaha and Loughborough University \\ mwohar@mail.unomaha.edu
}

March 1, 2017

\footnotetext{
${ }^{*}$ We thank Mark Freeman, Dimitris Chronopoulos, Fotios Papadimitriou, Michel Robe, Elisabeth Bui and participants at the IFABS Annual Conference 2012 and BAFA Annual Conference 2013 for very helpful comments and suggestions.
} 


\title{
Stock Returns Forecasting with Metals: \\ Sentiment vs. Fundamentals
}

\begin{abstract}
Using six prominent metal commodities, we provide evidence on the out-of-sample forecasting of stock returns for the market indices of the G7 countries, for which there is little prior evidence in this context. We find precious metals (Gold and Silver) can improve forecast accuracy relative to the benchmark and performs well compared to forecast combinations. From an economic gains perspective, forecasting returns provides certainty equivalent gains in a market-timing strategy for the G7 countries. These certainty equivalent gains are large enough to make active portfolio management attractive, even for individual investors. Gains remain after considering reasonable transaction costs.
\end{abstract}

Keywords: Return forecasting, G7, Commodities, Transaction Costs, Forecast Combinations. JEL: C53, G11, G17. 


\section{INTRODUCTION}

This paper is amongst the first to consider whether a wide range of metal commodity returns can forecast aggregate market equity returns out-of-sample (OOS) ${ }^{1}$. Metal returns can broadly impact stock returns $^{2}$ via two channels. First, they could impact industry costs if an industrial metal (such as aluminum or copper) is used as an input. ${ }^{3}$ For example, metal commodity price movements could be timely indicators of global supply and demand for raw materials or production activity. A second potential impact mechanism for metals is that precious metal commodity price movements could contain information about time-variation in investor risk preferences (or sentiment). That is, metals, such as gold or silver, are an important asset class for investors; therefore commodity returns could reflect changes in investor preferences. ${ }^{4}$ Sockin and Wang (2015) develop a theoretical model that demonstrates that metal prices signal the strength of the global economy. With the growth in exchange traded funds (ETFs), which must purchase and hold the commodities backing traded units, speculative demand and investor

1 Metals can be classified into four groups: precious metals, ferrous metals, non-ferrous metals and minor metals. The six major non-ferrous metals, also referred to as industrial metals, include aluminium, copper, nickel, lead, platinum, zinc and tin. All of these are traded on the LME . Aluminium and copper are the two most important non-ferrous metals by value, both extensively used across the entire range of industry and construction applications.

2 A 2015 IMF report states: "Base metals - such as iron ore, copper, aluminum and nickel - are the lifeblood of global industrial production and construction. Shaped by shifts in supply and demand, they are a valuable weathervane of change in the world economy.” In the academic literature, Jacobsen et al (2015) state that: "rising industrial metals prices are frequently seen as signaling an overheating economy and inflation" and Sockin and Wong (2015) state that: "prices of key industrial commodities can serve as price signals for the strength of the global economy."

3 Garner (1989) shows that commodity prices lead CPI inflation and gives two reasons: (1) the production process uses commodities as inputs and (2) commodity prices 'respond more rapidly than the prices of manufactured goods and services to demand pressures or supply shocks' as markets are more responsive to current events. In addition, Jacobsen, Marshall, and Visaltanachoti (2015) state that: One other potential explanation for the predictive ability of industrial metal returns to stock returns is production asset pricing. That is, industrial metals are important inputs in the production process. Finally, Black, Klinkowska, McMillan, and McMillan (2014) state that "Commodity prices respond to changes in expected demand and supply and have been shown to display predictive power for future output growth (e.g. Bakshi, Panayotov, Skoulakis 2011; Jacobsen et al., 2015). Therefore, changes in commodity prices can reveal information about future economic conditions (cash flows and macroeconomic risk), which are equally related to changes in stock prices.”

$4 \quad$ Smales (2014) reports an asymmetric response to news releases in which negative news sentiment leads to a greater contemporaneous response in the returns of gold futures than that of positive news. Zhang and Laws (2013) finds a strong contemporary relationship between precious metals and investor sentiment. Thorarinsson and Eshraghi (2013) find that the sentiment of the Chairman of the Federal Reserve in the US affects the returns of gold and silver. Baele, Bekaert, Inghelbrecht, and Wei (2014) document that flight-to-safety episodes coincide with increases in the VIX and decreases in consumer sentiment indicators. They also document that during flight-tosafety episodes that precious metals, specifically gold, behaves in a completely different manner than other commodities. 
preferences more easily affect price. For example, silver held by ETFs has grown from around 100 tons in 2006 to over 1000 tons by 2011 (see Rubino 2011). Recent studies find some evidence of in-sample stock return predictability by using commodity returns (see for example Jacobsen, Marshall, and Visaltanachoti, 2008; Jahan-Parvar, Vivian, and Wohar, 2012); however, little OOS evidence exists in this context. ${ }^{5}$ One contribution of this paper is to provide new OOS evidence on forecast accuracy and economic value using 2002-2011 as the OOS period. We also incorporate transaction costs into economic value tests. Our approach enables a wide range of transaction costs to be easily considered and is demonstrated for the manipulation proof measure of certainty equivalent gains proposed by Goetzmann, Ingersoll, Spiegel, and Welch (2007). Transaction costs are potentially important to incorporate into economic value measures since trading strategies require frequent portfolio rebalancing.

Prior OOS studies generally do not consider commodities in general, or metals specifically, as return predictors; this applies both to US studies and international studies. The focus has been on macro variables and fundamental variables based on dividends and earnings. ${ }^{6}$ In general, this literature finds that OOS predictability does not lead to large economic gains. ${ }^{7}$ We utilize the G7 equity markets and study if metal returns are useful for forming forecasts.

This paper extends the prior literature in several dimensions. First, we provide an extensive analysis of the OOS forecasting ability of different types of metals including both industrial metals and precious metals. Combination forecasts have been documented to outperform most other forecast methods. Thus, we examine the performance of a simple average forecast combination and investigate

5 Driesprong, Jacobsen and Maat (2008) provide some evidence in the context of one vital commodity, crude oil. They find limited significance for crude oil as a predictor of developed stock market returns either insample or out-of-sample. Chng (2009) provides evidence on links between commodity and equity markets as well as documenting some out-of-sample gains from forecasts of natural rubber. Jacobsen et al use an industrial metal index (for which copper and aluminum have major weight) and individually copper and aluminum returns. Jacobsen show predictive ability for metals for economic indicators and several Western stock indices (Japan being the exception). A working paper by $\mathrm{Hu}$ and Xiong (2013) that suggests that copper has predictive ability for global economic strength at the daily level.

Bossaerts and Hillion (1999), Goyal and Welch (2008) and Giot and Petitjean (2011) use fundamentalprice ratios and macro variables. Rapach, Wohar, and Rangvid (2005) use macro variables. Rapach and Wohar (2009) and McMillan and Wohar (2011) use the dividend-price ratio, while Jordan and Vivian (2011) use a wider range of fundamental ratios and their growth adjusted counterparts.

7 For example, Goyal and Welch (2008) and Campbell and Thompson (2008). 
whether including all individual models or just the industrial metal or precious metal subset in the combination perform best. Prior literature finds that for aggregate stock returns forecast combinations outperform the benchmark (Rapach, Strauss, and Zhou, 2010; Jordan and Vivian, 2011; Jordan, Vivian and Wohar, 2014). In contrast, we find mixed OOS evidence that forecast combination of all models provide statistically better forecasts than the benchmark for G7 stock returns. However, when only forecasts from precious metals are combined there is more OOS support that combinations outperform single predictor models. Our results are consistent with the idea that model predictions are subject to noise and adding noisy predictions to an average forecast can actually reduce forecast accuracy. Our evidence suggests that substantial improvements in forecast accuracy of G7 stock returns is primarily confined to the precious metal predictors.

Second we examine if regression model forecasts could enhance investors’ portfolio performance in real-time. This is important not only because they provide estimates of the economic value of forecasts to investors but also because they enable out-of-sample forecast accuracy results to be verified. ${ }^{8}$ The economic value of return forecasts provides an alternative metric by which the usefulness of out-ofsample forecasts can be assessed. This gives additional insight beyond that provided by out-of-sample forecast accuracy tests. These economic value estimates weight forecasts differently from forecast accuracy tests (Cenesizoglu and Timmermann, 2012) and thus, provide complementary evidence. The economic value of return forecasts has not previously been extensively tested using metals as predictors.

Third, we provide evidence from equity trading strategies which are based on incorporating commodities, in particular metal prices, into the information set. Our trading strategy evidence is particularly valuable because it investigates if return forecasts can help improve the asset allocation decision (between the equity market and the risk-free asset). It also provides an estimate of the magnitude

8 Inoue and Kilian (2004) and Cochrane (2008) suggest it is useful to verify out-of-sample forecast accuracy results. They present some convincing arguments for why in-sample tests are as reliable as out-of-sample tests of forecast accuracy. 
of possible gains to investors and practitioners. We investigate the economic value of predictability under the manipulation proof methodology of Goetzmann, et al. (2007).

Finally, we explore how robust forecast gains are to reasonable transaction costs. This is especially important in light of the recent paper by Moreno and Olmeda (2007). They demonstrate that much of the predictability documented in the short-horizon forecasting literature is not exploitable once transaction costs are incorporated. Trading costs have been largely ignored in the forecasting literature. The few studies which do model costs tend to simply provide a point estimate of the break-even costs (e.g. Della Corte et al., 2010) or estimate results for a given level of costs (e.g. Driesprong et al., 2008). In contrast, we provide an important extension to the literature by examining in detail how economic gains fluctuate as transaction costs vary. For example, our cost implementation strategy accounts for the fact that an investor will trade less under higher transaction costs. Thus, contrary to prior cost adjustments it is possible for our strategy to be more profitable with higher transaction costs if the number of trades are reduced and on average more profitable trades remain. Considering how gains are influenced by the cost of an investment strategy is important as it determines which investor classes could profitably use the strategy. Once transaction costs are incorporated, we find that Silver and Gold provide substantial gains for an investor that engages in market timing. Thus, substantial economic value can be earned via dynamic trading strategies relative to the benchmark by incorporating information from precious metals. These economic gains are robust to the imposition of reasonable transaction costs. We find that the economic gains from predictive forecasts are potentially more substantial than that suggested from the standard and purely statistical approach based on reductions in the mean square forecast error (MSFE).

From a practical perspective, our results also suggest implementing forecast combination strategies using precious metals for the G7 markets could help investors to rotate their portfolios across different asset classes. Market timing strategies based on predictability could well be operational given that ETF's for the G7 markets are widely available. Therefore, precious metal returns are likely to provide useful information to investors in the short-term. Most importantly, after reasonable transaction costs are considered, we demonstrate that forecast gains are available even to individual investors. 


\section{DATA DESCRIPTION}

We use six metal commodities as predictors including two precious metals (gold and silver) and four nonferrous or industrial metals (aluminum, copper, nickel and platinum). Nonferrous metals are base metals that do not include iron. Precious metals capture investor risk preference (or sentiment) as these metals are considered as safe havens. Thus, precious metals may capture time variation in risk aversion in the market. Nonferrous metals capture industrial production as these metals are primarily used for production of intermediate and finished goods. Thus, nonferrous metals may capture changes in economic activity.

Raw data is collected from the first week of 1985 until the last week of 2011. All raw series are denominated in US dollars to avoid the results being driven by the differently denominated currencies. ${ }^{9}$ There are several selection criteria for including a metal as a predictor: (1) it is covered by Thomson Datastream, (2) spot price data is available from at least 1985, (3) more than 95\% of price changes are non-zero, (4) the maximum correlation with other commodities is less than $0.9 .{ }^{10}$ We begin the OOS forecast evaluation period in 2002 week 2, which allows for a large OOS test period of 520 observations; the 260 observations prior to 2002 week 2 are used to optimize parameters in some of the combination models.

The data is primarily from Thomson Datastream. Table 1 provides a summary of descriptive statistics for our sample of commodities. We report the mean, the standard deviation, the minimum, and the maximum (log) return for each commodity, for each sector, and for each of the G7 market returns. The G7 market returns are based on the Datastream compiled indices with the exception of the US where

$9 \quad$ The US dollar is the correct currency denomination as most commodities are traded in terms of US dollars and a realistic trading strategy would likely utilize ETFs, which are primarily traded on the US stock exchanges in terms of US dollars.

10 The main commodities that had correlations of more than 0.9 with each other were alternative commodity instruments for the same or similar underlying commodities (e.g., alternative gold indices). We also undertook some robustness tests using futures data for 11 commodities (including Gold and Silver); the commodity futures return is generally very highly correlated with the spot return. Empirical results on forecast accuracy using either spot or futures returns are very similar. 
we use the S\&P 500. We use Wednesday-to-Wednesday returns to include weekend returns for commodities and for the US and Canadian equity returns; to avoid any possible look-ahead bias in stock returns for the other countries we used Thursday-to-Thursday returns. There are several interesting comparisons. First, we report the aggregate G7 country return summary in Panel A. There is a distinct difference between common law countries (Canada, United Kingdom, United States) and those from Nepoleonic code law countries (France, Germany, Italy and Japan). ${ }^{11}$ The standard deviation is lower for common law countries, which range from 0.0235 to 0.0266 , compared to those for bank or code law countries, which range from 0.0296 to 0.0337 . Even though common law countries tend to have lower standard deviations, the common law countries tend to also have higher average returns. The mean returns for common law countries range from 0.0018 to 0.0021 , while those from bank and code countries (excluding France, which has a mean return of 0.0024 ) range from 0.0010 to 0.0019 . Thus, the common law countries dominate (in a mean-variance sense) most of the bank-code countries. CN (Canada), UK (United Kingdom), and US United States) dominate DE (Germany), IT (Italy), and JP (Japan).

\section{[INSERT TABLE 1 AROUND HERE]}

Panel B of Table 1 provides the summary statistics for the returns on metals. The average nominal returns (RET) vary substantially across nonferrous metals from $0.0004(0.04 \%$ per week or $2.1 \%$ per year compounded) for aluminum, up to 0.0013 (0.13\% per week or 6.99\% per year compounded) for copper. The mean return does not vary much across precious metals from 0.0011 for platinum and silver to 0.0012 for gold. The standard deviation of returns varies substantially across both metal types from 0.0282 for aluminum to 0.0467 for nickel, while it varies from 0.0217 for gold to 0.0388 for silver. Returns on gold dominate returns on aluminum and nickel, while gold almost dominates copper (in that

11 Legal systems founded on the Napoleonic Code differ from the Common Law system. The Common Law judges base their decisions on precedent of past decisions. In legal systems based on Napoleonic Code judges are supposed to rule based on the legal code set by the legislature. 
copper has a much higher standard deviation while its mean return is only 0.0001 higher than that of gold). Platinum and silver dominate nickel. Panel C of Table 1 reports correlations between the variables. As is well known the correlations between G7 stock returns are positive and on average about 0.5. The correlation between metals is typically more moderate with average values of around 0.35 . However, there are some cases of higher correlations with for example high correlations between neighboring countries such as Canada and US as well as Germany and France.

\section{METHODOLOGY}

\subsection{Assessing the Impact of Individual Variables}

Individual Autoregressive Distributive Lagged (ARDL) models are used to estimate the linkage between the dependent, lagged dependent and a potential predictor variable (including its lag). An ARDL model is a dynamic general specification which uses the lags of the dependent variable and the lagged and contemporaneous values of the independent variables, through which both the short-run effects can be directly estimated and the long-run equilibrium relationship can be indirectly estimated. These ARDL(1,1) models take the form of (1) below.

$$
r_{t+1}=\alpha+\beta_{j} r_{t}+\lambda_{j} x_{t}+\varepsilon_{t+1}
$$

This model is employed to estimate the one week-ahead forecasts of stock returns using a recursive expanding window. Let $\mathrm{r}_{\mathrm{t}+1}=\mathrm{y}_{\mathrm{t}+1}-\mathrm{y}_{\mathrm{t}}$, where $\mathrm{y}_{\mathrm{t}+1}$ is the log-level of stock price index (including re-invested dividends) at time $\mathrm{t}+1$ (week). $r_{t+1}$ is linear in both the potential predictor variables (i.e. $\mathrm{x}_{\mathrm{t}}$ ) as

well as the lagged dependent variable. The parameter $\alpha$ is a constant. The parameter $\beta_{\mathrm{j}}$ denote the impact of the lagged dependent variable, and the $\lambda_{\mathrm{j}}$ capture the effect of the potential predictor variable. Finally, $\varepsilon_{t+1}$ is an error term. For the estimation of stock returns, 6 ARDL models are generated for each of the 6 metals used as explanatory variables. 
The models generated are used to conduct one week-ahead out-of-sample forecasts of stock returns; given this frequency of data it is important to control for first order autocorrelation in index returns (Boudoukh et al., 1994). These forecasts are then compared to the respective benchmark models which take the form of a pure autoregressive (AR) model. The AR(1) benchmark model estimates the dependent variable (aggregate market returns in our case) using one lag of the dependent variable. The form of the benchmark model is the same as in (1) when all the $\lambda_{\mathrm{j}}$ 's $=0$.

\subsection{Forecast Combinations}

Empirical as well as theoretical evidence (see Clemen and Winkler, 1986; Rapach and Strauss, 2010; Stock and Watson, 2003; 2004; and Yang, 2004) indicates that forecast combining generally improves the predictive ability of models because it includes more variables or potential predictors, thus increasing the amount of information used in generating forecasts. These combination methods can be described below in (2):

$$
\hat{r}_{C B, t+1 \mid t}=\sum_{i=1}^{n} w_{i, t} \hat{r}_{i, t+1 \mid t}
$$

where $\hat{f}_{\mathrm{CB}, t+1 \mathrm{v} t}$ is a combination forecast of the stock return (of interest), $\hat{f}_{i, t+1 \mathrm{v} t}$, is the ARDL(1,1) model forecast of variable $\mathrm{i}$ for period $\mathrm{t}+1$ conditional on information available at period $\mathrm{t} . \mathrm{w}_{\mathrm{i}, \mathrm{t}}$ is the weight at time $t$ on the forecast from variable $\mathrm{i}$. The weights, $\mathrm{w}_{\mathrm{i}, \mathrm{t}}$, sum to unity. The forecast combination method used in this paper is just a simple average of individual model forecasts (the mean). i.e. the forecasts are equally weighted.

\subsection{Tests of Equal Forecast Accuracy and Encompassing}

In the case of nested models, Clark and McCracken (2001) and McCracken (2007) develop a set of asymptotics that allow for an out-of-sample test of equal population-level predictive ability between two nested models. They show that, in the context of linear, Ordinary Least Squares estimated models, a number of different statistics can be employed to test for equal forecast accuracy and forecast 
encompassing, despite the fact that the models are nested. To statistically assess the performance of the models we report results from McCracken's (2007) Mean Square Error F test (MSF-F test) ${ }^{12}$. The MSE-F statistic is a one-sided test for equal forecast accuracy.

$$
M S E-F=-(T-1-R)\left[1-\frac{\sum_{t=R}^{T-1} \hat{u}_{b, t+1}^{2}}{\sum_{t=R}^{T-1} \hat{u}_{i, t+1}^{2}}\right],
$$

More specifically MSE-F is formulated under the null that the forecast error from the unrestricted (regression) model $\left(u_{i}\right)$ is equal to or larger than (inferior to) the forecast error from the benchmark $\left(u_{b}\right)$. In our paper, apart from one robustness test, the unrestricted model an ARDL(1,1) forecast or a combination forecast, while the benchmark is an AR(1) model. A rejection of the null hypothesis indicates that the regression model has superior forecast performance than the benchmark. Critical values are provided in McCracken (2007) for one-step ahead forecasts.

The Clark and West (2007) Mean Square Predicted Error adjusted statistic (MSPE-adjusted) is straightforward to compute. Define

$$
\tilde{d}_{i, t+1}=\hat{u}_{b, t+1}^{2}-\left[\hat{u}_{i, t+1}^{2}-\left(\hat{r}_{b, t+1}-\hat{r}_{i, t+1}\right)^{2}\right]
$$

and

then regressing the series $\left\{\tilde{d}_{i, t+1}\right\}_{t=R}^{T-1}$. on a constant; MSPE-adjusted is the t-statistic corresponding to the constant (also referred to as the CW-t statistic) . This is also a one-sided test of forecast accuracy, where the null hypothesis is the unrestricted (regression) model is equal to or larger than (inferior to) that from the benchmark regression. This is the same hypothesis tested by the McCracken (2007) MSE-F test, however the CW-t test adjusts for the upward bias in MSPE caused by the additional parameter estimation

12 We also implemented Clark and McCracken's (2001) Encompassing Test (ENC-NEW). Results are qualitatively similar to those for MSE-F. If equal forecast accuracy is rejected then the regression model forecast also encompasses the AR(1) benchmark model. In the interests of brevity we report only MSE-F. 
error in the alternative model (which includes additional predictors that are zero) under the null hypothesis.

\subsection{Measuring Economic Value}

Our final set of empirical tests deal with the economic value of forecasts. We analyze if portfolio allocations could have been improved by following the regression model rather than the AR(1) benchmark. We consider a simple asset allocation strategy in the spirit of Kong et al. (2011). ${ }^{13}$ For each week we examine the model forecasts for the market return. If the market index return forecast is greater than the risk-free rate then we invest in the market index (portfolio weight in the market index is 1) for that week, otherwise we invest purely in the risk-free rate for that week.

We implement Goetzmann et al.’s (2007, hereafter GISW) certainty equivalent measure of abnormal performance. Since this is a certainty equivalent measure, it means that risk preferences are controlled. We adapt this measure to include trading costs $\left(\mathrm{c}_{\mathrm{t}+1}\right)$ by deducting these from the investment return in months when the portfolio composition is altered, i.e., $\mathrm{c}_{\mathrm{t}+1}>0$ if the portfolio holding changes at time $\mathrm{t}+1$ and $\mathrm{c}_{\mathrm{t}+1}=0$ otherwise. Our method of controlling differs from many prior papers that just subtract a transaction cost from profits in that in our measure costs inherently measures the value of information in the signal to the cost of transacting on that signal before entering a trade. Thus, it is possible under our cost-adjusted strategy that profits could be higher with higher transaction costs. This situation could happen if the strength of the weaker signals were eliminated due to trading costs so that only stronger, more profitable, trades survived. The cost-adjusted GISW measure we use is given by

13 Since economic value tests can involve many changes in portfolios, transaction costs can be an important factor to control. Using simple methods allows us to develop an intuitive method to incorporate transaction costs. 


$$
\begin{aligned}
G I S W= & \frac{1}{1-\Gamma}\left[\ln \left(\frac{1}{T-1-R} \sum_{t=R}^{T-1}\left(\frac{1+r_{i, t+1}-c_{i, t+1}}{1+r_{f, t+1}}\right)^{1-\Gamma}\right)-\ln \left(\frac{1}{T-1-R} \sum_{t=R}^{T-1}\left(\frac{1+r_{b, t+1}-c_{b, t+1}}{1+r_{f, t+1}}\right)^{1-\Gamma}\right)\right] \\
& \text { where: } \Gamma=\frac{\ln \left[E\left(1+\bar{r}_{m}\right)\right]-\ln \left(1+\bar{r}_{f}\right)}{\operatorname{Var}\left[\ln \left(1+\bar{r}_{m}\right)\right]}
\end{aligned}
$$

The GISW measure looks at the average performance of a portfolio relative to the risk-free rate $\left(\mathrm{r}_{\mathrm{f}, \mathrm{t}+1}\right)$. We examine the difference between the return performance of portfolio selected by model i $\left(\mathrm{r}_{\mathrm{i}, \mathrm{t}+1}\right)$ with that of the $\operatorname{AR}(1)$ benchmark $\left(r_{b, t+1}\right)$. An advantage of the GISW measure is that it can be difficult to manipulate. The parameter $\Gamma$ is set to reflect the overall reward (excess return) to risk (variance) ratio for the market index ( $\mathrm{r}_{\mathrm{m}}$ is the market index return) based upon the actual sample data. This means that risk is explicitly adjusted for and hence the GISW measure is a certainty equivalent measure. It also reduces the possibility of manipulation and incorrect inference.

To generate confidence intervals for the economic value measure we implemented a bootstrap procedure consistent with Lux (2011) and Jordan et al., (2016). Pseudo samples were created for the country return index $\left(\mathrm{r}_{\mathrm{t}}\right)$ and each metal return $\left(\mathrm{x}_{\mathrm{t}}\right)$. For each pseudo sample, we then generated return forecasts for each model using equation (1) and generated combination forecasts using equation (2). We then used these forecasts (based on the pseudo sample) to estimate the GISW measure in turn under each level trading cost $(0 \%, 0.2 \%, 0.5 \%$ and $1 \%)$. The GISW value for each model-trading cost pair is then stored. We repeated the process 1000 times to generate an empirical distribution of GISW gains. Then for each model we ordered the empirical distribution and took the $900^{\text {th }}, 950^{\text {th }}$ and $990^{\text {th }}$ values as the $10 \%$, $5 \%$ and $1 \%$ critical value for the GISW measure.

\section{OUT-OF-SAMPLE STOCK RETURN FORECASTS}

Could investors' actually utilize metal commodity based models to benefit from more accurate predictions of future stock returns? This issue is of importance to both practitioners and academics alike. 
Asset managers, economic policymakers, as well as traders all need accurate estimates of future market returns. A natural question arises concerning whether metal commodity returns contain valuable information for equity return forecasts and if so, does the predictability come from nonferrous or precious metals?

\subsection{OOS Forecast Accuracy (Individual ARDL Forecasts)}

Table 2 shows various forecast results for individual commodity predictors using an ARDL(1,1) model. Specifically, the 1-week forecast results against an AR(1) benchmark are shown. We find that the precious metals strongly predict future market index returns. With the exception of Japan, the individual forecast models beat the benchmark at the 1-week horizon according to the superscripted McCracken (2007) MSE-F test and subscripted for the Clark-West (2007) MSPE adjusted test. At the 5\% significance level, only aluminum has predictability in 4 of 7 countries according to the McCracken MSE-F test and in only 2 of 7 countries according to the Clark-West MSPE adjusted test. Nickel, copper, and platinum have no predictability at the $5 \%$ significance level.

\section{[INSERT TABLE 2 AND TABLE 3 AROUND HERE]}

Precious metals, like gold and silver, provide the most consistent results of predictability. The source of this predictability may be the aggregate level of market risk aversion due to the traditional role these commodities play as safe havens (or hedge assets). ${ }^{14}$ Gold and silver also provide the largest gains over using an AR(1) benchmark. These gains can be sizable. For example, the relative mean squared forecast error (RMSFE) of silver compared to the benchmark is 0.983 when forecasting the Canadian index returns at the one-week horizon. This indicates the forecast error is reduced by $1.7 \%(1-0.983)$ when silver is used as a predictor for the Canadian market index.

14 Jahan-Parvar et al. (2012) find that precious metals granger cause most other commodities at short horizons. 
On the other hand, industrial metals (aluminum, nickel, copper, and platinum) have limited OOS forecast power for the G7 market returns. This is perhaps surprising given that industrial metal price changes could reflect global economic production and thus are a leading indicator of global demand.

Overall, combining forecasts from all models (AV. METALS) provides some gain relative to the benchmark, apart from in Japan. Results are stronger when the forecasts from only precious metals are combined (AV. PM); results are weaker when only the forecasts from industrial metals are combined (AV. IM). One explanation for this is that since the industrial metals have little forecast power adding them to the combined forecast introduces noise and widens the prediction error. The strong results for the precious metals combination reinforce the individual model results where Gold and Silver were the best individual performing metals. However, it is interesting that the average of all combinations fails to outperform the average of just the precious metals. This result seems to add to the finding of Jordan, Vivian and Wohar (2014) in a different context that widening the set of predictor variables used for combinations can worsen forecast performance if the additional forecast variables are noisy. In summary, combining forecasts from different commodity models provides some statistically significant evidence of gains over the benchmark, which is strongest when just the precious metal forecasts are combined.

We implement a recursive estimation technique and an AR(1) benchmark in Table 2. To test the robustness of the metals performance we have considered two alternatives. Firstly, we examine if the results are robust to the inclusion of additional control variables. Here we considered reasonable variables which are available at a weekly horizon. We include the country-specific equity index dividend yield and bond index return (unavailable for Italy) as well as two global measures which are the change in the VIX index and the oil return. As can be seen in Table 3 Panel A, the results are very similar to Table 2, although it is worth noting that the benchmark (MSFE) has increased suggesting the benchmark in Table 2 is a more appropriate benchmark. Secondly, we examine if the results are robust to estimation via a rolling window of 260 weeks rather than a recursive window which includes all available data up to the forecast date. Again we find the results in Table 3 Panel B relative to the benchmark are remarkably similar to Table 2, however, the benchmark consistently has larger MSFEs compared to the recursively 
estimated benchmark. Given the robustness of the main results in this analysis we proceed in the remainder of the paper to just report from recursive estimation and an AR(1) benchmark as in Table 2.

\subsection{Economic Gains}

What is the economic value of return forecasts? Can regression forecasts based on nonferrous or precious metals increase risk-adjusted returns? That is, does information on investor sentiment or aggregate production have value for forecasting market indices?

Table 4 examines the asset allocation decision between equities and riskless debt. Portfolios comprise either $100 \%$ equity or $100 \%$ risk-free debt depending on whether equity or debt is forecast to have a higher return. The benchmark is the AR(1) model and we use the GISW manipulation proof method to measure risk-adjusted return performance. Since each weekly strategy induces a different percent of trades (see \%TRADE columns), it is important to control for transaction costs. We do this by implementing the transaction costs using the method outlined in section 3.4 (Equation 5) and by graphing the results.

For the asset allocation results in Table 4, we find (with zero trading costs) that there is economic gain to forecasting with metals. Germany and France are the exceptions. Only silver and platinum have predictive value in these two countries. There is broad predictability using metals in the other G7 country indices. However, the statistical difference from 0 of these gains are more consistently apparent for the precious metals (Gold and Silver) than for the industrial metals. Furthermore, in Japan, while economic gains are consistently reported, (virtually) none of these are statistically different from zero; we suggest the economic situation with minimal interest rates and deflation in Japan are likely responsible for the wider confidence intervals on economic value compared to other countries.

\section{[INSERT TABLE 4 AROUND HERE]}


When costs are considered, ${ }^{15}$ economic gains remain. At $0.2 \%$ transaction costs, $100 \%$ of the G7 country indices are predictable at both statistically and economically significant levels for gold, silver, and aluminum. The fact that gains due to predictability increase with transaction costs at first might be surprising. However, there are opposing constraints. The first is how often a strategy trades, on average how profitable a trade is, and the cost of trading. As the trade of cost increases, the frequency of trade decreases. This can result in a strategy using stronger signals before implementing a trade. If the gain from stronger predictability due to a stronger signal outweighs the additional cost of transacting, then an increase in profitability can result.

The economic gains from predicting indices with metals changes in two ways with increasing transaction costs. First, with few exceptions (other than from zero to a small incremental transaction cost), the large gains from bagging achieved over the AR(1) benchmark decrease with the size of transaction costs. There is a clear relationship to the cost of trading and the number of transactions employed by the optimal strategy. As transaction costs increase, the number of transactions falls dramatically. Second, there is a schism in predictability between nonferrous metals and precious metals. For reasonable costs (i.e., $0.2 \%$ and $0.5 \%$ per transaction), predictions using gold and silver provide economic value. At $0.2 \%$, both gold and silver add value for $100 \%$ of the G7 countries. At $0.5 \%$, gold adds value for $57 \%$ and silver add value for $71 \%$ of the G7 countries. Furthermore many of these gains for precious metals are distinguishable from zero. On the other hand, for nonferrous metals, only predictions using aluminum maintains economic value after transaction costs and this value diminishes quickly with cost. Aluminum adds value for $100 \%$ of the G7 country indices at $0.2 \%$ cost, but fails to predict at higher costs. There is little evidence for predictability using copper, nickel, or platinum.

In terms of combinations, these also generally perform best when transaction costs are taken to be zero with economic gains being positive in all cases for the average of precious metals and in 5 of 7 countries for the average of all metals; the average of precious metals also generates larger gains than the

15 See section 3.4 and equation 5 for how costs are implemented. 
average of all metals in each country when trading costs are zero. However, as trading costs increase these gains tend to weaken (as with the individual model results). With transaction costs of $0.5 \%$ we find the average of all metals only beats the benchmark in two out of seven countries (Italy and Japan), whereas the average of precious metals beats the benchmark in four countries.

One possible interpretation of the transaction cost results is that investor risk preference (sentiment) has a larger effect in magnitude on aggregate stock index returns than production. Precious metals, if thought of as a proxy for market sentiment, retains value for predicting market indices even at $0.5 \%$ transaction costs. On the other hand, most nonferrous metals as proxies of production have little to no predictability if transaction costs are considered. The exception, aluminum, only adds economic value to predictions with transaction costs limited to $0.2 \%$. Thus, gains from market timing with bagging appears to be realizable only in markets with reasonable transaction costs, which is likely the scenario for market and sector investors. ${ }^{16}$ These gains are more likely achieved via predicting investor sentiment than economic production.

What is interesting here is that the results clearly show that gains can be made, not only for the marginal trader, but for a small investor as well. Small investors can trade indices for less than $0.5 \%$ per trade and if the funds are in a tax-deferred retirement fund, these trade costs are probably much closer to the $0.2 \%$ level. Thus, forecasting has real economic value to a broad array of investors.

The fact that trade decisions change with cost size induces large fluctuations or a large noise element into the forecast performance. This occurs if a particularly large good or bad forecast result is added or deleted. Figure 1 shows the large changes in a strategy's forecast performance for the market/risk-free rotation for each of the forecast strategies considered. This is true across country-metal pairs. The large swings in value are clearly visible for all strategies. Furthermore, when trading costs

16 The dependence on costs is due to the existence of two effects, sometimes acting in opposite directions. As costs increase: (i) the strategy which trades more gets penalized more on average reducing its certainty equivalent gain; and (ii) the choice of when to trade changes (i.e., trade frequency is reduced) and this affects certainty equivalent gains in an ambiguous way, e.g., it may be positive or negative depending on whether the marginal trade is ex-post a success or failure. Ultimately, as trade costs get large enough, the forecast strategy and the benchmark will make no trades and the GISW will converge to zero. 
increase above $0.5 \%$ per trade, we find that gains converge to 0 . This is because the forecasted weekly returns from the regression model is rarely large enough to induce a trade when the costs are this high and hence the position held converges to the same strategy as the benchmark. The take away from Figure 1 and Table 4 is that trade frequency is an important factor in a strategy that faces realistic constraints and costs.

\section{[INSERT FIGURE 1 AROUND HERE]}

\subsection{Encompassing Tests}

Table 5 provides evidence on whether the various metals contain independent information for predicting the G7 index returns. This table reports forecast encompassing tests on pairs of metals for each of the G7 country returns. To determine independence of information we use the Harvey, Leybourne and Newbold (HLN, 1998) forecast encompassing test. The HLN test has the same test statistic as the ClarkWest (2007), which is outlined in section 3.3 and equation 3. However, the two tests have a different interpretation and the HLN test can be applied to compare non-nested models. The null hypothesis of the HLN test is that the country return listed in a column has a weight of zero when combined with the country return listed in a row. The alternative hypothesis is that the variable in the column (on top) is not encompassed by the variable in the row (on the left), i.e., the column variable contains information above and beyond that in the row variable that improves the forecast of the country index return. A p-value of less than 0.05 indicates that the weight on the country return in the column metal is statistically different from 0 at the $5 \%$ level of significance or better when this metal is added as a second explanatory variable to the single regression model of index return on the row metal. For example, for Panel G US, silver (Column metal) and aluminum (Row metal) the p-value of 0.046 indicates that we can reject the null hypothesis that the forecast based on silver has a weight of zero when added to the forecast based on aluminum. Thus, the information contained in silver that helps forecast the US index return is not encompassed by the information in aluminum that is useful in forecasting the US return. Thus, silver adds 
new information over and above that contained in the aluminum forecast for forecasting the US index return.

\section{[INSERT TABLE 5 AROUND HERE]}

A clear pattern emerges. The information contained in the industrial metals copper, nickel, and platinum is encompassed by the information in both precious metals (gold and silver) and in aluminum. Thus, adding these three industrial metals to a forecast model provides little value. On the other hand, silver is rarely encompassed and thus provides independent information for forecasting the G7 index returns above and beyond that contained in either gold or any of the industrialized metals. Finally, neither aluminum nor gold are encompassed by any of the other industrial metals. However, both aluminum and gold are encompassed by silver. Thus, if silver is included in the model, there is little economic gain by adding aluminum or gold to the model. Overall these results provide insight into why the average of all forecasts does not generally perform as well as the average of just precious metals in either the forecast accuracy tests or estimates of economic value. The average of all forecasts is including information from industrial metals, such as nickel and copper, which is already encompassed by the precious metals; hence by excluding these superfluous forecasts the average of just precious metals is able to perform better.

\section{CONCLUSION}

This paper studies the fundamental question of whether future stock returns can be accurately forecast using metal returns. It extends prior literature which focuses on in-sample predictability in this context (Jacobsen et al., 2015; Jahan-Parvar et al., 2012). In contrast, this paper focuses on out-of-sample (OOS) forecasting of stock returns employing the market index of each of the G7 countries. It tests if metals (precious or industrial) can forecast stock returns. Additionally we examine if combining methods proposed to overcome poor return predictability can improve forecast accuracy or increase economic value. We also provide new evidence on how robust the economic value forecasts are to trading costs. 
This analysis does not simply examine one point estimate of trading cost but studies how gains vary across a wide range of different levels of trading cost.

We provide evidence on the questions: (i) Can stock return forecasts based on metal returns beat an $\mathrm{AR}(1)$ benchmark in real time? (ii) Can combining forecasts using various combination methods improve statistical and economic value of forecasts? (iii) Are gains from forecasting methods realizable to individual investors and practitioners? (iv) How sensitive are economic gains to transaction costs?

Firstly, we find the statistical value of predictability is mixed across predictor commodities. Only precious metal commodity returns (Gold and Silver) provide consistent and substantial improvements in OOS forecast accuracy of stock returns. Precious metal returns are impacted by variation in investor risk aversion and thus could proxy for time-varying expected returns. We provide some validation for this hypothesis by reporting that precious metals forecast almost all G7 country market returns (with the exception of Japan). ${ }^{17}$ In contrast, most industrial metals do not provide large or reliable gains. Our findings are robust across several methods that have been proposed to improve predictability such as forecast combinations.

Secondly, in tests of equal forecast accuracy, forecast combinations of all models do not perform particularly well against the benchmark in our setting. This finding contrasts with prior US market return evidence that forecast combination methods often perform well when a wide range of different predictors are used (Rapach et al., 2010). We postulate that high levels of noise drive this result. ${ }^{18}$ Our results for forecast combinations from just precious metals are more favorable. Subsequent diagnostic analysis from encompassing tests provides an explanation for this. Three of the industrial metals (Copper, Nickel and Platinum) provide no additional information beyond that contained in Silver or Gold, respectively (i.e. the

17 These results are also consistent with Jordan (2012) who finds that long-term reversals can be explained by time-variation in the coefficients of the CAPM. If investor risk preferences change over time, this would result in time-varying coefficients in an asset pricing model.

18 We consider the case of combining forecasts from linear models using a simple average combination specifications. However, our results for combinations might not apply to other models that: i) combine forecasts from non-linear models, ii) use a Bayesian model averaging technique (e.g. as in Della Corte, Sarno and Valente, 2009) iii) doesn't constrain the weights on the individual models to sum to 1 (Sarno, Thornton and Valente, 2005). 
industrial metals are encompassed). Thus these three industrial metals just add noise.

Thirdly, we extensively examine the impact of transaction costs upon the gains from trading strategies. Much prior literature overlooks transaction costs and those studies which examine it explicitly focus on either the break-even trading cost (e.g. Della Corte et al., 2011) or a fixed trading cost (e.g. Driesprong et al., 2008). In contrast, we model trading costs and graph how the economic value of predictability is affected by changes in the level of trading cost. This provides a more complete picture of the sensitivity of performance gains to trading costs. The analysis of trading strategies in this paper also differs from the prior literature in that the strategy implemented by an investor is re-calculated depending upon the level of trading cost; thus an increase in trading cost might not necessarily decrease the economic gains from implementing the strategy. Our dynamic cost methodology is implemented for an asset allocation strategy (between equity and debt). The empirical results indicate that within a realistic transaction cost range, that forecasts from precious metals may prove useful to practitioners.

There are two main themes that should be taken from our results. First, tests on economic value provide more consistent and stronger evidence of return predictability than purely forecast accuracy measures (consistent with some prior literature using individual predictive regressions e.g. Della Corte et al., 2010). This is true across several methodologies, including ARDL models and combination methods and may reflect different ways in which forecasts are weighted for statistical and economic tests. The economic value of forecasting market returns can be substantial. The second insight is from an implementation perspective. There is interplay between gains, trade frequency, and transaction costs. Once trade costs are considered, we find that economic gains are available to a wide range of investors, including small investors. These gains could be particularly valuable in a tax-deferred account, e.g., a retirement account. Thus, active management, even for small investors may be feasible. 


\section{BIBLIOGRAPHY}

Aiolfi, M. and Timmermann, A. (2006). Persistence in forecasting performance and conditional combination strategies. Journal of Econometrics, 135(1-2): 31-53.

Baele, L.; Bekaert, G.; Inghelbrecht, K.; Wei, M., (2014), Flights to Safety, National Bank of Belgium Working Paper No. 230, Available: http://ssrn.com/abstract=2160858

Bai, J., and Ng, S. (2002). Determining the number of factors in approximate factor models. Econometrica 70: 191-221.

Bakshi G, Panayotov G, Skoulakis G. (2011). The Baltic Dry index as a predictor of global stock returns, commodity returns and global economic activity. Working paper. Available: http://ssrn.com/abstract=1747345 [3 September 2014.

Bates, J.M. and Granger, C.W. (1969). The Combination of Forecasts. Operations Research Quarterly, 20: 451-468.

Black, A. J., Klinkowska, O., McMillan, D. G., and McMilland, F. J. (2014). Forecasting Stock Returns: Do Commodity Prices Help? Journal of Forecasting, 33(8), p. 627-639.

Bossaerts, P. and Hillion, P. (1999). Implementing Statistical Criteria to Select Return Forecasting Models: What do We Learn? Review of Financial Studies, Vol. 12, No. 2, 405-428.

Boudoukh, J., Richardson, M. P., and Whitelaw, R. F. (1994). A tale of three schools: Insights on autocorrelations of short-horizon stock returns. Review of Financial studies, Vol. 7, No. 3, 539-573.

Campbell, J. and Thompson, S. (2008), Predicting Excess Stock Returns Out of Sample: Can Anything Beat the Historical Average?, Review of Financial Studies, Vol. 21, No.4, 1509-1531

Cenesizoglu, T. and Timmermann, A. (2012). Do return prediction models add economic value?, Journal of Banking and Finance, 36 (11), 2974-2987

Central Intelligence Agency (2006-05-16). "The World Factbook: Canada". Central Intelligence Agency. Retrieved 2007-05-06.

Chan, Y.L., Stock, J.H. and Watson, M.W. (1999). A dynamic factor model framework for forecast combination. Spanish Economic Review, 1(2): 91-121.

Chen, Z., and Epstein, L. G., 2002. Ambiguity, risk and asset returns in continuous time. Econometrica, 70, 1403-1443.

Chng, M. T., 2009. Economic linkages across commodity futures: Hedging and trading implications. Journal of Banking and Finance 33 (5), 958-970.

Clark T and M. McCracken (2001), "Tests of Equal Forecast Accuracy and Encompassing for Nested Models,” Journal of Econometrics, Vol. 105, No. 1, pp. 85-110.

Clark, Todd E. and Kenneth D. West (2007), “Approximately Normal Tests for Equal Predictive Accuracy in Nested Models,” Journal of Econometrics 138, 291-311.

Clemen, R.T. and Winkler, R.L. (1986). Combining economic forecasts. Journal of Business and Economic Statistics, 4(1): 39-46.

Cochrane J. H. (2008), The dog that did not bark: A defense of return predictability. Review of Financial Studies, Vol. 21, No.4, 1533-1575.

Della Corte, P., Sarno, L., and Tsiakas, I. (2009). An Economic Evaluation of Empirical Exchange Rate Models. Review of Financial Studies 22: 3491-3530.

Della Corte, P., Sarno, L., and Valente, G. (2010). A century of equity premium predictability and the consumption-wealth ratio: An international perspective. Journal of Empirical Finance 17: 313-331.

Driesprong, G., Jacobsen, B., and Maat, B., (2008). Striking oil: another puzzle? Journal of Financial Economics 89, 307-327. 
Garlappi, L., Uppal, R., Wang, T., 2007. Portfolio selection with parameter and model uncertainty: A multi-prior approach. Review of Financial Studies, 20, 41-81.

Garner, C.A., 1989. Commodity prices: Policy target or information variable?: Note. Journal of Money, Credit and Banking, 21(4), 508-514.

Giot, P. and Petitjean, M. (2011), On the statistical and economic performance of stock return predictive regression models: an international perspective. Quantitative Finance, 11:2, 175-193.

Goetzmann, W., Ingersoll, J, Speigel, M., and Welch, I. (2007), Portfolio Performance Manipulation and Manipulation-proof Performance Measures, Review of Financial Studies, Vol. 20, No. 5, 1503-1546.

Goyal A and Welch I (2008), A comprehensive look at the Empirical performance of the equity premium prediction, Review of Financial Studies, Vol. 21, No.4, 1455-1508.

Han, Y. F., 2012. State uncertainty in stock markets: How big is the impact on the cost of equity? Journal of Banking \& Finance, 36, 2575-2592.

Hu, C. and Xiong, W. (2013). Are Commodity Futures Prices Barometers of the Global Economy? Princeton University Working Paper.

Hansen, L. P., Sargent, T. J., 2001. Acknowledging misspecification in macroeconomic theory. Review of Economic Dynamics, 4, 519-535.

Inoue, A., and Kilian, L. (2004), In-Sample or Out-of-Sample Tests of Predictability: Which One Should We Use? Econometric Reviews, Vol. 23, No. 4, 371-402.

Inoue, A., Kilian, L. (2008). How useful is bagging in forecasting economic time series? A case study of U.S. CPI inflation. Journal of the American Statistical Association 103:511-522.

IMF Direct, (2015) "Metals and Oil: A Tale of Two Commodities." https://blogimfdirect.imf.org/2015/09/14/metals-and-oil-a-tale-of-two-commodities/

Jacobsen, B., Marshall, B. R., and Visaltanachoti, N. (2008), Return Predictability Revisited, SSRN working paper, http://papers.ssrn.com/sol3/papers.cfm?abstract id=1284856

Jacobsen, B., Marshall, B. R., and Visaltanachoti, N. (2015). Stock Market Predictability and Industrial Metal Returns, 23rd Austalasian Finance and Banking Conference Paper. SSRN: http://ssrn.com/abstract=1660864

Jahan-Parvar, M., Vivian, A. and Wohar, M. E. (2012), Predictability and Underreaction in Industry-Level Returns: Evidence from Commodity Markets, SSRN working paper, http://papers.ssrn.com/sol3/papers.cfm?abstract_id=2005365

Jiang, C., Jordan, S. J., and Parikh, B. R., (2013), Macroeconomic Uncertainty, Risk, and Country Index Returns: International Evidence. Working paper, University of Memphis.

Jordan, S. J. (2012), Time-varying Risk and Long-term Reversals Journal of International Business Studies, 45(2): 123-142.

Jordan, S. J. and Vivian, A. J. (2011), Forecasting Stock Returns Internationally: Can Fundamental-price Models Beat the Historical Average? IFABS 2011 Conference (Rome) Paper.

Jordan, S. J., Vivian, A., and Wohar, M. E. (2014). Sticky prices or economically-linked economies: The case of forecasting the Chinese stock market. Journal of International Money and Finance, 41, 95-109.

Jordan, S. J., Vivian, A., and Wohar, M. E. (2016). Forecasting Market Returns: Bagging or Combining. International Journal of Forecasting, forthcoming.

Kogan, L., Wang, T., 2003. A simple theory of asset pricing under model uncertainty. Unpublished working paper, Massachusetts Institute of Technology and The University of British Columbia, http://web.mit.edu/lkogan2/www/Papers/KoganWang2003.pdf. 
Kong, A., Rapach, D.E., Strauss, J. and Zhou, G. (2011), Predicting Market Components Out of Sample: Asset Allocation Implications, Journal of Portfolio Management, 37(4), 29-41 .

Lux,T., (2011) Sentiment Dynamics and Stock Returns, Empirical Economics 41 (3), 663-679.

McCracken, M.W. (2007), “Asymptoptics for Out-of-Sample Tests of Granger Causality,” Journal of Econometrics 140, 719-752.

McMillan, D.G. and Wohar, M. E. (2011), Sum of the parts stock return forecasting: international evidence, Applied Financial Economics 21: 837-845.

Moreno, D., and Olmeda, I. (2007). Is the predictability of emerging and developed stock markets really exploitable? European Journal of Operational Research 182 (1), 436-454.

Ozoguz, A., (2009), Good Times or Bad Times? Investors' Uncertainty and Stock Returns. Review of Financial Studies, 22(11): 4378-4422.

Rapach, D.E. and Strauss, J.K. (2008). Forecasting U.S. employment growth using forecast combining methods. Journal of Forecasting, 27: 75-93.

Rapach, D.E. and Strauss, J.K. (2010). Bagging or combining (or both)? An analysis based on forecasting U.S. employment growth. Econometric Reviews, 29(5-6): 511-533.

Rapach, D.E., Strauss JK, Zhou GF (2010), Out-of-Sample Equity Premium Prediction: Combination Forecasts and Links to the Real Economy. Review of Financial Studies, Vol. 23, No. 2. 821862.

Rapach, D. E., M. E. Wohar (2009), Multi-period portfolio choice and the intertemporal hedging demands for stocks and bonds: International evidence. Journal of International Money and Finance, Vol. 28, No. 3, 427-453.

Rapach, D. E., M. E. Wohar and J. Rangvid (2005) Macro Variables and International Stock Return Predictability. International Journal of Forecasting, Vol. 21, No. 1, 137-166.

Rubino, J. (2011) ETFs promise cheap diversification, liquidity, and perhaps unintended consequences for systemic risk. CFA Magazine, Sept-Oct, 30-33.

Sarno, L., Thorton, J. and Valente, G., (2005) Federal Funds Rate Prediction, Journal of Money, Credit and Banking, 37: 449-471.

Smales, L. A., (2014), News Sentiment in the Gold Futures Market, Journal of Banking and Finance, 49, 275-286.

Sockin, M. and Wong, W., (2015). Information frictions and commodity markets. Journal of Finance, 70(5): 2063-2098.

Stock, J. H., Watson, M. W. (2003). Forecasting output growth and inflation: The role of asset prices. Journal of Economic Literature 41: 788-829.

Stock, J. and Watson, M. (2004), Combination Forecasts of Output Growth in a Seven-Country Data Set, Journal of Forecasting, 23: 405-430.

Thorarinsson, K. and Eshraghi, A., (2013), The Financial Impact of Fed Policy Statements and Chairman Sentiment: The Case of Gold and Silver Markets, SSRN Working paper, http://ssrn.com/abstract=2278239

Uppal, R. and Wang, T., 2003. Model misspecification and underdiversification. Journal of Finance, 58, 2465-2486.

Yang, Y. (2004). Combining forecasting procedures: some theoretical results. Econometric Theory, 20(1): 176-222.

Zhang, Y. and Laws, J., (2013), Investor Sentiment and Forecasting Ability: Evidence from COT Reports in Precious Metal Futures Markets, SSRN Working paper, http://ssrn.com/abstract=2382299 
Table 1: Descriptive Statistics (1985:1-2011:52)

Panel A: Log Stock Return - Aggregate market and sectors

\begin{tabular}{|c|c|c|c|c|c|c|c|}
\hline & $\mathbf{C N}$ & DE & FR & $\mathbf{I T}$ & $\mathbf{J P}$ & UK & US \\
\hline Mean & 0.0020 & 0.0019 & 0.0024 & 0.0016 & 0.0010 & 0.0021 & 0.0018 \\
\hline SD & 0.0264 & 0.0296 & 0.0295 & 0.0337 & 0.0307 & 0.0266 & 0.0235 \\
\hline Min & -0.2025 & -0.1487 & -0.1544 & -0.1708 & -0.1295 & -0.2249 & -0.1666 \\
\hline Max & 0.1019 & 0.1194 & 0.1183 & 0.1301 & 0.1494 & 0.1315 & 0.1020 \\
\hline \multicolumn{8}{|c|}{ Panel B: Log Commodity Returns } \\
\hline & ALUMINIUM & NICKEL & COPPER & PLATINUM & GOLD & SILVER & \\
\hline Mean & 0.0004 & 0.0009 & 0.0013 & 0.0011 & 0.0012 & 0.0011 & \\
\hline SD & 0.0282 & 0.0467 & 0.0358 & 0.0310 & 0.0217 & 0.0388 & \\
\hline Min & -0.1836 & -0.1996 & -0.1706 & -0.1930 & -0.1238 & -0.2598 & \\
\hline Max & 0.1425 & 0.3207 & 0.1702 & 0.1515 & 0.1370 & 0.2102 & \\
\hline
\end{tabular}

Panel C: Correlation Matrix

\begin{tabular}{|c|c|c|c|c|c|c|c|c|c|c|c|c|c|}
\hline & $\mathrm{CN}$ & DE & FR & IT & $\mathbf{J P}$ & UK & US & $\begin{array}{c}\text { ALUMI } \\
\text { NIUM } \\
\end{array}$ & NICKELC & COPPER & $\begin{array}{c}\text { PLATI } \\
\text { NUM }\end{array}$ & GOLD & SILVER \\
\hline $\mathrm{CN}$ & 1.000 & & & & & & & & & & & & \\
\hline DE & 0.533 & 1.000 & & & & & & & & & & & \\
\hline FR & 0.543 & 0.812 & 1.000 & & & & & & & & & & \\
\hline IT & 0.474 & 0.690 & 0.721 & 1.000 & & & & & & & & & \\
\hline JP & 0.376 & 0.403 & 0.409 & 0.342 & 1.000 & & & & & & & & \\
\hline UK & 0.591 & 0.710 & 0.738 & 0.633 & 0.395 & 1.000 & & & & & & & \\
\hline US & 0.757 & 0.559 & 0.568 & 0.468 & 0.408 & 0.601 & 1.000 & & & & & & \\
\hline ALUMINIUM & 0.322 & 0.210 & 0.182 & 0.182 & 0.157 & 0.228 & 0.215 & 1.000 & & & & & \\
\hline NICKEL & 0.327 & 0.206 & 0.174 & 0.148 & 0.136 & 0.211 & 0.222 & 0.444 & 1.000 & & & & \\
\hline COPPER & 0.374 & 0.224 & 0.199 & 0.182 & 0.113 & 0.265 & 0.253 & 0.537 & 0.484 & 1.000 & & & \\
\hline PLATINUM & 0.303 & 0.162 & 0.164 & 0.172 & 0.153 & 0.187 & 0.125 & 0.293 & 0.185 & 0.290 & 1.000 & & \\
\hline GOLD & 0.253 & 0.119 & 0.109 & 0.102 & 0.063 & 0.143 & -0.008 & 0.216 & 0.166 & 0.252 & 0.542 & 1.000 & \\
\hline SILVER & 0.329 & 0.141 & 0.120 & 0.137 & 0.115 & 0.180 & 0.098 & 0.266 & 0.201 & 0.263 & 0.534 & 0.660 & 1.000 \\
\hline
\end{tabular}

Notes: Data is weekly and based on Wednesday closing information over the period 1985 week 1 to 2011 week 52 . The Top Row identifies the country market index (Panel A) or commodity market (Panel B). The G7 countries are included in the data sample: Canada (CN), Germany (DE), France (FR), Italy (IT), Japan (JP), the United Kingdom (UK), and the United States (US). Our metals include nonferrous metal (Aluminium, Nickel, Copper and Platinum) and precious metals (Gold, and Silver).Mean is the sample average, SD is the standard deviation, Min is the minimum value and Max is the maximum value. 
Table 2: ARDL(1,1) model Forecast Performance

1 week forecast horizon over 2002:2-2011:52

\begin{tabular}{|c|c|c|c|c|c|c|c|c|c|c|c|c|}
\hline & $\mathbf{C N}$ & & DE & & FR & & IT & & JP & UK & US & \\
\hline AR (MSFE) & 0.0011 & & 0.0011 & & 0.0011 & & 0.0012 & & 0.0008 & 0.0009 & 0.0007 & \\
\hline ALUMINIUM & 0.997 & & 0.993 & $\begin{array}{l}* * * \\
* *\end{array}$ & 0.993 & $\begin{array}{l}* * * \\
* *\end{array}$ & 0.995 & $\begin{array}{l}* * \\
*\end{array}$ & 1.003 & $0.997^{* *}$ & 1.000 & \\
\hline NICKEL & 1.002 & & 0.999 & & 1.000 & & 1.001 & & 1.001 & 1.002 & 1.002 & \\
\hline COPPER & 1.002 & & 0.998 & & 1.000 & & 1.001 & & 1.003 & 1.003 & 1.002 & \\
\hline PLATINUM & 0.998 & & 1.000 & & 1.000 & & 1.001 & & 1.005 & 0.999 & 1.004 & \\
\hline GOLD & 0.994 & $\begin{array}{l}* * * \\
*\end{array}$ & 0.991 & $\begin{array}{l}* * * \\
* *\end{array}$ & 0.994 & $\begin{array}{l}* * * \\
* *\end{array}$ & 0.994 & $\begin{array}{l}* * * \\
* *\end{array}$ & 1.002 & $0.995_{*}^{* * *}$ & 0.997 * & $\begin{array}{l}* * \\
*\end{array}$ \\
\hline SILVER & 0.983 & $\begin{array}{l}* * * \\
* * *\end{array}$ & 0.991 & $\begin{array}{l}* * * \\
* *\end{array}$ & 0.992 & $\begin{array}{l}* * * \\
* *\end{array}$ & 0.992 & $\begin{array}{l}* * * \\
* *\end{array}$ & 1.002 & $0.989^{* * *}$ & 0.995 * & $\begin{array}{l}* * \\
* *\end{array}$ \\
\hline AV. IM & 0.999 & & 0.997 & $\begin{array}{l}* \\
*\end{array}$ & 0.998 & & 0.999 & * & $1.002 *$ & $1.000 *$ & $1.001 *$ & \\
\hline AV. PM & 0.987 & $\begin{array}{l}* \\
* * *\end{array}$ & 0.991 & $\begin{array}{l}* \\
* * *\end{array}$ & 0.992 & $\begin{array}{l}* \\
* *\end{array}$ & 0.992 & $\begin{array}{l}* \\
* * *\end{array}$ & $1.001 *$ & $0.991 *$ & 0.995 & $\begin{array}{l}* \\
* *\end{array}$ \\
\hline AV. METALS & 0.994 & $\begin{array}{l}* \\
* * \\
\end{array}$ & 0.994 & $\begin{array}{l}* \\
* * \\
\end{array}$ & 0.996 & $\begin{array}{l}* \\
*\end{array}$ & 0.996 & $\begin{array}{l}* \\
*\end{array}$ & $1.002 *$ & $\begin{array}{r}0.996 * \\
* \\
\end{array}$ & 0.999 & \\
\hline
\end{tabular}

Notes: The column) titles identify one of the G7 the countries. The Second Row [AR(MSFE)] reports the mean-squared forecast error for the benchmark AR(1) model. The other rows report the ratios of the mean-squared forecast errors for each ARDL(1,1) model to the mean-squared forecast error of the AR(1) model. Each ARDL model includes one lagged dependent variable and the lagged commodity price change for the commodity in column 1. Bold typeface denotes if the mean-squared forecast error from the individual model is smaller than the AR(1) model. CN is Canada, DE is Germany, FR is France, IT is Italy, JP is Japan, UK is United Kingdom and US is United States of America. ${ }^{* * *}, * *, *$ denote statistical significance at the $1 \%, 5 \%$ and $10 \%$ levels of statistical significance respectively which is superscripted for the McCracken (2007) MSE-F test and subscripted for the Clark-West (2007) MSPE adjusted test. 
Table 3: Forecast Performance Robustness Tests

Panel A: ARDL(1,1) model Forecast Performance - Controls Included

1 week forecast horizon over 2002:2-2011:52

\begin{tabular}{|c|c|c|c|c|c|c|c|c|c|c|c|}
\hline & CN & & DE & & FR & & IT & & JP & UK & US \\
\hline AR+CTL (MSFE & 0.001073 & & 0.001126 & & 0.001121 & & 0.001179 & & 0.000791 & 0.000943 & 0.000671 \\
\hline ALUMINIUM & 0.998 & & 0.994 & $\begin{array}{l}* * * \\
*\end{array}$ & 0.995 & $\begin{array}{l}* * \\
*\end{array}$ & 0.996 & $* *$ & 1.002 & $0.998^{*}$ & 1.001 \\
\hline NICKEL & 1.001 & & 1.000 & & 1.001 & & 1.001 & & 1.001 & 1.001 & 1.001 \\
\hline COPPER & 1.001 & & 0.999 & & 1.001 & & 1.002 & & 1.002 & 1.003 & 1.001 \\
\hline PLATINUM & 1.000 & & 1.000 & & 1.001 & & 1.002 & & 1.004 & 1.000 & 1.005 \\
\hline GOLD & 0.994 & *** & 0.991 & $\begin{array}{l}* * * \\
* *\end{array}$ & 0.994 & $* * *$ & 0.996 & $\begin{array}{l}* * \\
*\end{array}$ & 1.002 & $0.995^{* *}$ & $0.997^{* *}$ \\
\hline SILVER & 0.983 & $\begin{array}{l}* * * \\
* * *\end{array}$ & 0.992 & $\begin{array}{l}* * * \\
* * \\
\end{array}$ & 0.993 & $\begin{array}{l}* * * \\
* *\end{array}$ & 0.994 & $\begin{array}{l}* * * \\
* \\
\end{array}$ & 1.002 & $0.990_{* *}^{* * *}$ & $0.996_{*}^{* *}$ \\
\hline AV. IM & 0.999 & & 0.998 & $\begin{array}{l}* \\
*\end{array}$ & 0.999 & & 1.000 & & 1.002 & 1.000 & 1.001 \\
\hline AV. PM & 0.988 & $\begin{array}{l}* * * \\
* *\end{array}$ & 0.991 & $\begin{array}{l}* * * \\
* *\end{array}$ & 0.993 & $\begin{array}{l}* * * \\
* *\end{array}$ & 0.994 & $\begin{array}{l}* * * \\
* *\end{array}$ & 1.001 & $0.992^{* * *}$ & 0.996 ** \\
\hline AV. METALS & 0.995 & $\begin{array}{l}* * \\
* * \\
\end{array}$ & 0.995 & $\begin{array}{l}* * \\
* * \\
\end{array}$ & 0.996 & $\begin{array}{l}* * \\
* * \\
*\end{array}$ & 0.997 & $\begin{array}{l}* \\
* * \\
\end{array}$ & 1.001 & $\begin{array}{r}0.997 \\
* * \\
* * \\
\end{array}$ & 0.999 \\
\hline
\end{tabular}

Panel B: ARDL(1,1) model Forecast Performance - Rolling 260 week (5 year) estimation

1 week forecast horizon over 2002:2-2011:52

\begin{tabular}{|c|c|c|c|c|c|c|c|}
\hline & $\mathbf{C N}$ & DE & FR & $\mathbf{I T}$ & JP & UK & US \\
\hline AR (MSFE) & 0.001085 & 0.001135 & 0.001131 & 0.001198 & 0.000793 & 0.000957 & 0.000681 \\
\hline ALUMINIUM & 1.003 & 1.002 & 1.000 & 1.002 & 1.009 & 1.003 & 1.000 \\
\hline NICKEL & 1.011 & 1.004 & 1.005 & 1.005 & 1.008 & 1.006 & 1.002 \\
\hline COPPER & 1.011 & 1.005 & 1.006 & 1.007 & 1.010 & 1.007 & 1.002 \\
\hline PLATINUM & 1.002 & 1.003 & 1.005 & 1.008 & 1.012 & 1.006 & 1.004 \\
\hline GOLD & 0.999 & $0.991_{* *}^{* * *}$ & $0.994_{*}^{* * *}$ & $0.997^{* *}$ & 1.005 & $0.996^{* *}$ & $0.997^{* *}$ \\
\hline SILVER & $0.991_{* *}^{* * *}$ & 1.001 & $0.9966_{*}^{* *}$ & 0.999 & 1.010 & $0.993_{* *}^{* * *}$ & $0.995^{* *}$ \\
\hline AV. IM & 1.004 & 1.002 & 1.002 & 1.003 & 1.008 & 1.004 & $1.001 *$ \\
\hline AV.PM & $0.992_{* *}^{* * *}$ & $0.995_{* *}^{* * *}$ & $0.994_{* *}^{* * *}$ & $\mathbf{0 . 9 9 7}{ }^{* *}$ & 1.005 & $0.993^{* * *}$ & $0.995^{*}$ \\
\hline AV. METALS & $\begin{array}{r}0.998 * \\
* \\
\end{array}$ & $0.999 *$ & $\begin{array}{r}0.998 * \\
* \\
\end{array}$ & 1.000 & 1.006 & 0.998 & $0.999 *$ \\
\hline
\end{tabular}

Notes: The column titles identify one of the G7 the countries. The Second Row [AR(MSFE)] reports the mean-squared forecast error for the benchmark. The other rows report the ratios of the mean-squared forecast errors for each ARDL $(1,1)$ model to the mean-squared forecast error of the AR(1) model. In Panel A both the AR(1) model and ARDL(1,1) models are augmented with control variables, which are the equity dividend yield, the 10 year government bond return index, the change in VIX (volatility index) and the WTI oil return. In Panel B the models are estimated using a 260 week rolling window. In Panel B each ARDL model includes one lagged dependent variable and the lagged commodity price change for the commodity in column 1. Bold typeface denotes if the mean-squared forecast error from the individual model is smaller than the AR(1) model. CN is Canada, DE is Germany, FR is France, IT is Italy, JP is Japan, UK is United Kingdom and US is United States of America. ***, **, * denote statistical significance at the $1 \%, 5 \%$ and $10 \%$ levels of statistical significance respectively which is superscripted for the McCracken (2007) MSE-F test and subscripted for the Clark-West (2007) MSPE adjusted test. 
Table 4: Economic Value of Trading Strategies using GISW measure - One week ahead over 2002:2-2011:52

Panel A: Canada

\begin{tabular}{|c|c|c|}
\hline \multirow[t]{2}{*}{$\mathbf{C N}$} & \multicolumn{2}{|c|}{$\operatorname{COST}=0$} \\
\hline & GISW & \% TRADE \\
\hline ALUMINIUM & $5.99^{* * *}$ & 0.53 \\
\hline NICKEL & $2.49^{* *}$ & 29.67 \\
\hline COPPER & 1.18 & 29.67 \\
\hline PLATINUM & 1.06 & 28.13 \\
\hline GOLD & $6.46^{* * *}$ & 25.82 \\
\hline SILVER & $7.99^{* * *}$ & 36.61 \\
\hline AV. IM & $2.16^{* *}$ & 28.13 \\
\hline AV. PM & $7.37^{* * *}$ & 30.44 \\
\hline AV. METALS & $3.48^{* * *}$ & 26.20 \\
\hline AR(p) & & 27.75 \\
\hline
\end{tabular}

\begin{tabular}{|c|c|c|c|}
\hline \multicolumn{2}{|c|}{$\mathrm{COST}=0.2 \%$} & \multicolumn{2}{|c|}{$\mathrm{COST}=0.5 \%$} \\
\hline GISW & \% TRADE & GISW & \% TRADE \\
\hline 0.49 & 7.69 & -1.10 & 1.27 \\
\hline-2.61 & 12.57 & -2.13 & 3.43 \\
\hline-2.63 & 11.67 & -0.96 & 3.25 \\
\hline-0.73 & 7.52 & -0.25 & 2.02 \\
\hline $1.76^{* *}$ & 9.43 & $1.04^{*}$ & 2.76 \\
\hline $1.13^{*}$ & 15.07 & $0.49^{*}$ & 2.77 \\
\hline-0.91 & 8.90 & -1.17 & 2.64 \\
\hline $1.94^{* *}$ & 11.16 & -0.70 & 2.51 \\
\hline \multirow[t]{2}{*}{-1.17} & 8.46 & -1.04 & 2.33 \\
\hline & 8.33 & & 2.06 \\
\hline
\end{tabular}

\begin{tabular}{|c|c|}
\hline \multicolumn{2}{|c|}{$\operatorname{COST}=1 \%$} \\
\hline GISW & $\%$ TRADE \\
\hline $1.18^{* * *}$ & 0.00 \\
\hline $2.02^{* * *}$ & 0.94 \\
\hline $3.03^{* * *}$ & 0.50 \\
\hline 0.13 & 0.72 \\
\hline $4.84^{* * *}$ & 0.44 \\
\hline $2.63^{* * *}$ & 0.77 \\
\hline $2.07^{* * *}$ & 0.50 \\
\hline $4.09^{* * *}$ & 0.48 \\
\hline $2.23^{* * *}$ & 0.50 \\
\hline & 0.75 \\
\hline
\end{tabular}

Panel B: Germany

\begin{tabular}{lrr}
\hline DE & \multicolumn{2}{c}{ COST $=$ 0 } \\
\hline & GISW & \% TRADE \\
\hline ALUMINIUM & $2.38{ }^{*}$ & 0.64
\end{tabular}
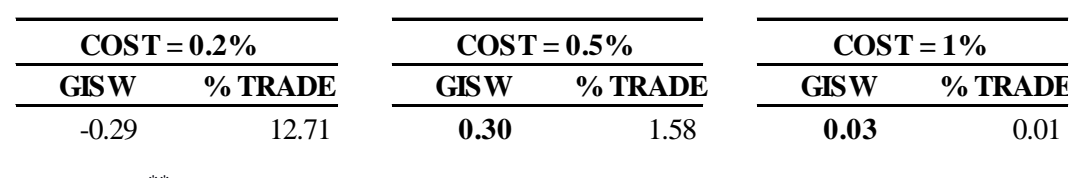

\begin{tabular}{lll} 
NICKEL & -5.59 & 25.05 \\
COPPER & -1.45 & 24.47 \\
PLATINUM & $\mathbf{1 . 0 0}$ & 17.73 \\
\hline GOLD & -2.44 & 26.59 \\
SILVER & $\mathbf{1 . 3 9}$ & 38.34 \\
\hline AV. IM & -1.84 & 21.39 \\
AV. PM & $\mathbf{2 . 2 8} *^{* *}$ & 29.29 \\
AV. METALS & -1.00 & 22.54 \\
\hline AR(p) & & 17.34 \\
\hline
\end{tabular}

\begin{tabular}{cccc}
$\mathbf{1 . 7 7}^{* *}$ & 5.47 & -1.21 & 0.33 \\
-1.30 & 6.84 & -1.50 & 0.44 \\
-0.57 & 4.37 & $\mathbf{0 . 3 6}$ & 0.59 \\
\hline $\mathbf{1 . 7 1}^{* *}$ & 7.14 & $\mathbf{1 . 5 9}^{* *}$ & 1.36 \\
$\mathbf{3 . 6 3}^{* *}$ & 12.06 & $\mathbf{0 . 5 5}{ }^{*}$ & 1.58 \\
\hline-0.04 & 5.36 & -0.97 & 0.35 \\
$\mathbf{1 . 1 0}^{*}$ & 8.75 & $\mathbf{0 . 7 6}$ & 1.21 \\
$\mathbf{0 . 2 2}$ & 5.10 & -0.47 & 0.29 \\
\cline { 4 - 5 } & 4.28 & & 0.62 \\
\hline
\end{tabular}

\begin{tabular}{ll}
0.00 & 0.00 \\
0.00 & 0.00 \\
0.00 & 0.00 \\
\hline-0.03 & 0.07 \\
0.00 & 0.00 \\
\hline 0.00 & 0.00 \\
0.00 & 0.00 \\
0.00 & 0.00 \\
\hline & 0.00
\end{tabular}


Panel C: France

\begin{tabular}{lcr}
\hline FR & \multicolumn{2}{c}{ COST = 0 } \\
\hline & GISW & \% TRADE \\
\hline ALUMINIUM & -0.44 & 0.40 \\
NICKEL & -0.63 & 5.01 \\
COPPER & -1.06 & 7.51 \\
PLATINUM & $\mathbf{0 . 3 6}$ & 5.01 \\
\hline GOLD & -1.51 & 10.02 \\
SILVER & $\mathbf{3 . 4 8}{ }^{* *}$ & 14.45 \\
\hline AV. IM & $\mathbf{0 . 3 2}$ & 7.51 \\
AV. PM & $\mathbf{2 . 8 1}$ & 10.40 \\
AV. METALS & -0.53 & 5.97 \\
\hline AR(p) & & 3.85 \\
\hline
\end{tabular}

Panel D: Italy

\begin{tabular}{|c|c|c|}
\hline \multirow[t]{2}{*}{ IT } & \multicolumn{2}{|c|}{ COST $=0$} \\
\hline & GISW & \% TRADE \\
\hline ALUMINIUM & $4.00{ }^{*}$ & 0.61 \\
\hline NICKEL & 0.86 & 21.97 \\
\hline COPPER & -0.41 & 27.94 \\
\hline PLATINUM & 0.13 & 19.27 \\
\hline GOLD & $4.34^{* *}$ & 33.33 \\
\hline SILVER & $2.36{ }^{*}$ & 37.96 \\
\hline AV. IM & $2.67^{*}$ & 23.31 \\
\hline AV.PM & $6.39^{* * *}$ & 31.79 \\
\hline AV. METALS & $2.17^{*}$ & 24.86 \\
\hline $\operatorname{AR}(p)$ & & 20.04 \\
\hline
\end{tabular}

Panel E: Japan

\begin{tabular}{lcr}
\hline JP & \multicolumn{2}{c}{ COST = 0 } \\
\hline ALUMINIUM & $\mathbf{1 . 8 8}$ & \% TRADE \\
NICKEL & $\mathbf{1 . 5 2}$ & 21.97 \\
COPPER & $\mathbf{1 . 3 3}$ & 27.94 \\
PLATINUM & -1.37 & 19.27 \\
\hline GOLD & $\mathbf{1 . 8 7}$ & 33.33 \\
SILVER & $\mathbf{2 . 2 1}$ & 37.96 \\
\hline AV. IM & $\mathbf{2 . 0 3}$ & 23.31 \\
AV. PM & $\mathbf{3 . 1 4}$ & 31.79 \\
AV. METALS & $\mathbf{1 . 1 7}$ & 24.86 \\
\hline AR(p) & & 20.04 \\
\hline
\end{tabular}

\begin{tabular}{|c|c|c|c|c|c|}
\hline \multicolumn{2}{|c|}{$\mathrm{COST}=0.2 \%$} & \multicolumn{2}{|c|}{$\mathrm{COST}=\mathbf{0 . 5 \%}$} & \multicolumn{2}{|c|}{$\mathrm{COST}=1 \%$} \\
\hline GISW & $\%$ TRADE & GISW & \% TRADE & GISW & \% TRADE \\
\hline $1.07^{*}$ & 5.53 & $0.96^{* *}$ & 1.01 & 0.00 & 0.00 \\
\hline-0.20 & 0.53 & 0.00 & 0.00 & 0.00 & 0.00 \\
\hline-0.59 & 0.84 & 0.00 & 0.00 & 0.00 & 0.00 \\
\hline 0.08 & 0.94 & 0.00 & 0.00 & 0.00 & 0.00 \\
\hline $1.29^{* *}$ & 2.95 & 0.10 & 0.17 & 0.00 & 0.00 \\
\hline $1.57^{* *}$ & 3.23 & -0.04 & 0.24 & 0.00 & 0.00 \\
\hline-0.30 & 0.46 & 0.00 & 0.00 & 0.00 & 0.00 \\
\hline 0.83 & 2.70 & 0.00 & 0.00 & 0.00 & 0.00 \\
\hline \multirow[t]{2}{*}{-0.29} & 0.61 & 0.00 & 0.00 & 0.00 & 0.00 \\
\hline & 1.23 & & 0.00 & \multicolumn{2}{|r|}{0.00} \\
\hline \multicolumn{2}{|c|}{$\mathrm{COST}=0.2 \%$} & \multicolumn{2}{|c|}{$\mathrm{COST}=0.5 \%$} & \multicolumn{2}{|c|}{ COST $=1 \%$} \\
\hline GISW & \% TRADE & GISW & \% TRADE & GISW & $\%$ TRADE \\
\hline $2.88{ }^{*}$ & 10.49 & -2.55 & 1.56 & 0.00 & 0.00 \\
\hline-0.20 & 6.04 & $1.04^{*}$ & 1.52 & 0.00 & 0.00 \\
\hline-1.49 & 6.98 & -0.29 & 1.19 & 0.00 & 0.00 \\
\hline-0.31 & 5.98 & -1.29 & 1.49 & 0.00 & 0.00 \\
\hline $4.30^{* *}$ & 11.17 & $1.86^{*}$ & 2.26 & 0.71 & 0.22 \\
\hline $4.34^{* *}$ & 12.04 & -0.82 & 2.42 & 0.00 & 0.00 \\
\hline-0.92 & 5.15 & -1.37 & 1.25 & 0.00 & 0.00 \\
\hline $4.75^{* *}$ & 10.55 & 0.29 & 1.96 & 0.00 & 0.00 \\
\hline \multirow[t]{2}{*}{0.50} & 5.99 & $0.85^{*}$ & 1.36 & 0.00 & 0.00 \\
\hline & $\overline{5.74}$ & & 1.43 & \multicolumn{2}{|r|}{0.00} \\
\hline \multicolumn{2}{|c|}{$\mathrm{COST}=0.2 \%$} & \multicolumn{2}{|c|}{$\operatorname{COST}=0.5 \%$} & \multicolumn{2}{|c|}{$\mathrm{COST}=1 \%$} \\
\hline GISW & \% TRADE & GISW & \% TRADE & GISW & \% TRADE \\
\hline 0.17 & 10.49 & -0.24 & 1.56 & 0.00 & 0.00 \\
\hline-0.63 & 6.04 & 0.39 & 1.52 & 0.00 & 0.00 \\
\hline-1.34 & 6.98 & 0.02 & 1.19 & 0.00 & 0.00 \\
\hline-1.01 & 5.98 & -0.31 & 1.49 & 0.00 & 0.00 \\
\hline 2.10 & 11.17 & -0.39 & 2.26 & 0.09 & 0.22 \\
\hline 1.10 & 12.04 & 0.38 & 2.42 & 0.00 & 0.00 \\
\hline 2.10 & 11.17 & -0.39 & 2.26 & 0.09 & 0.22 \\
\hline 1.10 & 12.04 & 0.38 & 2.42 & 0.00 & 0.00 \\
\hline \multirow[t]{2}{*}{1.79} & 10.55 & 0.30 & 1.96 & 0.00 & 0.00 \\
\hline & 5.74 & & 1.43 & & 0.00 \\
\hline
\end{tabular}


Panel F: UK

\begin{tabular}{lcr}
\hline UK & \multicolumn{2}{c}{ COST = 0 } \\
\hline & GISW & \% TRADE \\
\hline ALUMINIUM & $\mathbf{0 . 1 4}$ & 0.32 \\
NICKEL & 0.00 & 0.77 \\
COPPER & -0.31 & 4.43 \\
PLATINUM & $\mathbf{2 . 6 6}^{* *}$ & 3.08 \\
\hline GOLD & $\mathbf{2 . 2 6}$ & 11.18 \\
SILVER & $\mathbf{0 . 0 0}$ & 28.52 \\
\hline AV. IM & $\mathbf{0 . 5 9}$ & 1.54 \\
AV. PM & $\mathbf{1 . 7 2}{ }^{* *}$ & 16.57 \\
AV. METALS & $\mathbf{1 . 2 2}{ }^{*}$ & 2.70 \\
\hline AR(p) & & 0.77 \\
\hline
\end{tabular}

Panel G: US

\begin{tabular}{lcr}
\hline US & \multicolumn{2}{c}{ COST $=\mathbf{0}$} \\
\hline \multicolumn{1}{c}{ GISW } & \% TRADE \\
\hline ALUMINIUM & $\mathbf{1 . 0 8}{ }^{*}$ & 0.52 \\
NICKEL & $\mathbf{0 . 1 4}$ & 7.32 \\
COPPER & $\mathbf{0 . 4 9}$ & 8.09 \\
PLATINUM & -0.51 & 10.02 \\
\hline GOLD & $\mathbf{1 . 8 4}^{* *}$ & 29.87 \\
SILVER & $\mathbf{3 . 9 1}^{* * *}$ & 34.68 \\
\hline AV. IM & $\mathbf{0 . 9 6}$ & 8.48 \\
AV. PM & $\mathbf{3 . 4 2}{ }^{* * *}$ & 30.06 \\
AV. METALS & $\mathbf{3 . 1 3}{ }^{* * *}$ & 14.64 \\
\hline AR(p) & & 6.94 \\
\hline
\end{tabular}

\begin{tabular}{|c|c|c|c|}
\hline \multicolumn{2}{|c|}{ COST $=0.2 \%$} & \multicolumn{2}{|c|}{ COST $=0.5 \%$} \\
\hline GISW & \% TRADE & GISW & \% TRADE \\
\hline $1.09^{* *}$ & 2.22 & -0.13 & 0.17 \\
\hline-0.04 & 0.24 & 0.00 & 0.00 \\
\hline 0.08 & 0.39 & 0.00 & 0.00 \\
\hline-0.16 & 0.33 & 0.00 & 0.00 \\
\hline $0.80^{*}$ & 2.20 & -0.94 & 0.15 \\
\hline $3.86^{* * *}$ & 6.57 & $1.56^{* *}$ & 0.83 \\
\hline-0.10 & 0.15 & 0.00 & 0.00 \\
\hline $2.27^{* *}$ & 3.17 & 0.00 & 0.00 \\
\hline \multirow[t]{2}{*}{-0.35} & 0.20 & 0.00 & 0.00 \\
\hline & 0.22 & & 0.00 \\
\hline
\end{tabular}

\begin{tabular}{cr}
\hline \multicolumn{3}{c}{ COST $=1 \%$} \\
\hline GISW & \% TRADE \\
\hline 0.00 & 0.00
\end{tabular}

\begin{tabular}{cc}
0.00 & 0.00 \\
0.00 & 0.00 \\
0.00 & 0.00 \\
\hline 0.00 & 0.00 \\
0.00 & 0.00 \\
\hline 0.00 & 0.00 \\
0.00 & 0.00 \\
0.00 & 0.00 \\
\hline & 0.00 \\
\hline
\end{tabular}

\begin{tabular}{|c|c|c|c|}
\hline \multicolumn{2}{|c|}{$\mathrm{COST}=0.2 \%$} & \multicolumn{2}{|c|}{ COST $=0.5 \%$} \\
\hline GISW & \% TRADE & GISW & \% TRADE \\
\hline 0.11 & 3.82 & -0.91 & 0.31 \\
\hline-0.06 & 0.72 & 0.00 & 0.00 \\
\hline 0.15 & 0.92 & 0.00 & 0.00 \\
\hline-0.07 & 0.81 & 0.00 & 0.00 \\
\hline 0.54 & 3.54 & 0.00 & 0.00 \\
\hline $1.01 *$ & 7.60 & $0.77^{* *}$ & 0.64 \\
\hline-0.07 & 0.61 & 0.00 & 0.00 \\
\hline $1.31^{* *}$ & 4.59 & 0.02 & 0.07 \\
\hline \multirow[t]{2}{*}{0.07} & 0.84 & 0.00 & 0.00 \\
\hline & 0.64 & & 0.00 \\
\hline
\end{tabular}

\begin{tabular}{cr}
\hline \multicolumn{2}{c}{ COST $=$ 1\% } \\
\hline GISW & \% TRADE \\
\hline 0.00 & 0.00 \\
0.00 & 0.00 \\
0.00 & 0.00 \\
0.00 & 0.00 \\
\hline 0.00 & 0.00 \\
0.00 & 0.00 \\
\hline 0.00 & 0.00 \\
0.00 & 0.00 \\
0.00 & 0.00 \\
\hline & 0.00 \\
\hline
\end{tabular}

Notes:

Table 4 reports results for the difference in the GISW performance measure between the model in column 1 and the AR(1) benchmark. The strategy is that if the market is predicted to be higher than the risk-free rate then all of the investment is placed into the market portfolio for that week, otherwise all the investment is placed into the risk-free rate. The GISW gains are annualized by multiplying the weekly gain by 52. Confidence intervals for the GISW gains were estimated via a bootstrap procedure using 1000 repetitions as described in Section 3.4. ${ }^{* * *}$, ${ }^{* *}$, * denote statistical significance at the $1 \%, 5 \%$ and $10 \%$ levels of statistical significance respectively. \%TRADE is the proportion of periods in which the strategy changes. COST is the round-trip trading expenses; we provide results for zero cost $(0 \%)$ and three levels of positive round-trip trading cost $0.2 \%, 0.5 \%$ and $1 \%$. For the positive round-trip trading cost we average the GISW performance measure (and \% trading) across 21 point estimates from $0.1 \%$ below the cost to $0.1 \%$ above the cost. This is due to there being some noise in the data. We display results of each country for a wide range of trading costs in Figures 1 to 7. 
Table 5: ARDL(1,1) model Forecast Encompassing Tests

Panel A: Canada

\begin{tabular}{|c|c|c|c|c|c|c|}
\hline $\mathrm{CN}$ & ALUMINIUM & NICKEL & COPPER & PLATINUM & GOLD & SILVER \\
\hline ALUMINIUM & & 0.583 & 0.587 & 0.488 & 0.160 & 0.009 \\
\hline NICKEL & 0.165 & & 0.450 & 0.191 & 0.061 & 0.001 \\
\hline COPPER & 0.174 & 0.329 & & 0.210 & 0.078 & 0.003 \\
\hline PLATINUM & 0.346 & 0.599 & 0.601 & & 0.142 & 0.003 \\
\hline GOLD & 0.585 & 0.700 & 0.688 & 0.658 & & 0.021 \\
\hline SILVER & 0.822 & 0.861 & 0.843 & 0.907 & 0.839 & \\
\hline \multicolumn{7}{|c|}{ Panel B: Germany } \\
\hline DE & ALUMINIUM & NICKEL & COPPER & PLATINUM & GOLD & SILVER \\
\hline ALUMINIUM & & 0.705 & 0.726 & 0.664 & 0.194 & 0.193 \\
\hline NICKEL & 0.040 & & 0.220 & 0.439 & 0.017 & 0.037 \\
\hline COPPER & 0.050 & 0.476 & & 0.526 & 0.046 & 0.058 \\
\hline PLATINUM & 0.047 & 0.271 & 0.190 & & 0.023 & 0.036 \\
\hline GOLD & 0.345 & 0.876 & 0.812 & 0.907 & & 0.351 \\
\hline SILVER & 0.287 & 0.656 & 0.622 & 0.723 & 0.291 & \\
\hline \multicolumn{7}{|c|}{ Panel C: France } \\
\hline FR & ALUMINIUM & NICKEL & COPPER & PLATINUM & GOLD & SILVER \\
\hline ALUMINIUM & & 0.741 & 0.798 & 0.710 & 0.316 & 0.212 \\
\hline NICKEL & 0.034 & & 0.363 & 0.422 & 0.020 & 0.016 \\
\hline COPPER & 0.032 & 0.382 & & 0.384 & 0.026 & 0.015 \\
\hline PLATINUM & 0.038 & 0.391 & 0.338 & & 0.020 & 0.010 \\
\hline GOLD & 0.242 & 0.890 & 0.885 & 0.910 & & 0.213 \\
\hline SILVER & 0.314 & 0.868 & 0.873 & 0.915 & 0.538 & \\
\hline
\end{tabular}


Panel D: Italy

\begin{tabular}{lcccccc}
\hline IT & ALUMINIUM & NICKEL & COPPER & PLATINUM & GOLD & SILVER \\
\hline ALUMINIUM & & 0.676 & 0.784 & 0.725 & 0.227 & 0.176 \\
NICKEL & $\mathbf{0 . 0 6 0}$ & & 0.315 & 0.471 & $\mathbf{0 . 0 2 5}$ & $\mathbf{0 . 0 3 0}$ \\
COPPER & $\mathbf{0 . 0 4 9}$ & 0.408 & & 0.408 & $\mathbf{0 . 0 3 0}$ & $\mathbf{0 . 0 3 0}$ \\
PLATINUM & $\mathbf{0 . 0 5 1}$ & 0.433 & 0.261 & & $\mathbf{0 . 0 2 3}$ & $\mathbf{0 . 0 2 0}$ \\
GOLD & 0.321 & 0.740 & 0.756 & 0.778 & & 0.236 \\
SILVER & 0.372 & 0.718 & 0.736 & 0.793 & 0.408 & \\
\hline
\end{tabular}

Panel E: Japan

\begin{tabular}{lcccccc}
\hline JP & ALUMINIUM & NICKEL & COPPER & PLATINUM & GOLD & SILVER \\
\hline ALUMINIUM & & 0.166 & 0.306 & 0.466 & 0.179 & 0.245 \\
NICKEL & 0.403 & & 0.716 & 0.678 & 0.544 & 0.440 \\
COPPER & 0.317 & 0.161 & & 0.584 & 0.231 & 0.292 \\
PLATINUM & 0.194 & 0.151 & 0.211 & & 0.173 & 0.192 \\
GOLD & 0.328 & 0.286 & 0.515 & 0.591 & & 0.350 \\
SILVER & 0.292 & 0.196 & 0.347 & 0.568 & 0.218 & \\
\hline Panel F: UK & & & & & & \\
\hline UK & ALUMINIUM & NICKEL & COPPER & PLATINUM & GOLD & SILVER \\
\hline ALUMINIUM & & 0.701 & 0.832 & 0.534 & 0.231 & $\mathbf{0 . 0 5 8}$ \\
NICKEL & $\mathbf{0 . 0 7 4}$ & & 0.622 & 0.242 & $\mathbf{0 . 0 4 8}$ & $\mathbf{0 . 0 1 0}$ \\
COPPER & $\mathbf{0 . 0 4 1}$ & 0.171 & & 0.145 & $\mathbf{0 . 0 3 2}$ & $\mathbf{0 . 0 0 7}$ \\
PLATINUM & 0.209 & 0.617 & 0.709 & & 0.155 & $\mathbf{0 . 0 1 0}$ \\
GOLD & 0.441 & 0.826 & 0.868 & 0.698 & & $\mathbf{0 . 0 9 0}$ \\
SILVER & 0.600 & 0.814 & 0.859 & 0.858 & 0.652 & \\
\hline
\end{tabular}


Panel G: US

\begin{tabular}{lcccccc}
\hline US & ALUMINIUM & NICKEL & COPPER & PLATINUM & GOLD & SILVER \\
\hline ALUMINIUM & & 0.400 & 0.383 & 0.654 & 0.111 & $\mathbf{0 . 0 4 6}$ \\
NICKEL & 0.185 & & 0.465 & 0.739 & $\mathbf{0 . 0 3 9}$ & $\mathbf{0 . 0 2 2}$ \\
COPPER & 0.203 & 0.437 & & 0.631 & $\mathbf{0 . 0 5 9}$ & $\mathbf{0 . 0 3 1}$ \\
PLATINUM & $\mathbf{0 . 0 7 5}$ & 0.161 & 0.238 & & $\mathbf{0 . 0 1 6}$ & $\mathbf{0 . 0 0 8}$ \\
GOLD & 0.538 & 0.720 & 0.663 & 0.901 & & 0.204 \\
SILVER & 0.528 & 0.615 & 0.576 & 0.828 & 0.436 & \\
\hline
\end{tabular}

Notes: This table reports results of forecast encompassing tests on pairs of the country returns. The results are calculated for the MHLN test is the Harvey, Leybourne and Newbold (1998) forecast encompassing test. This test uses the same test statistic as the ClarkWest test. The null hypothesis is that the country return in Column has a weight of zero when combined with the country return in Row. A p-value of less than 0.05 indicates that the weight on the country return in Column is statistically different from 0 at the $5 \%$ level of significance or better. For example for Panel G US, Silver (Column) and Aluminium (Row) the p-value of 0.046 indicates that we can reject the null hypothesis that the forecast based on Silver has a weight of zero when combined with the forecast based on Aluminium. Thus, the Silver forecast is not encompassed by the Aluminium forecast, i.e., the Silver forecast adds new information over and above that contained in the Aluminium forecast. 


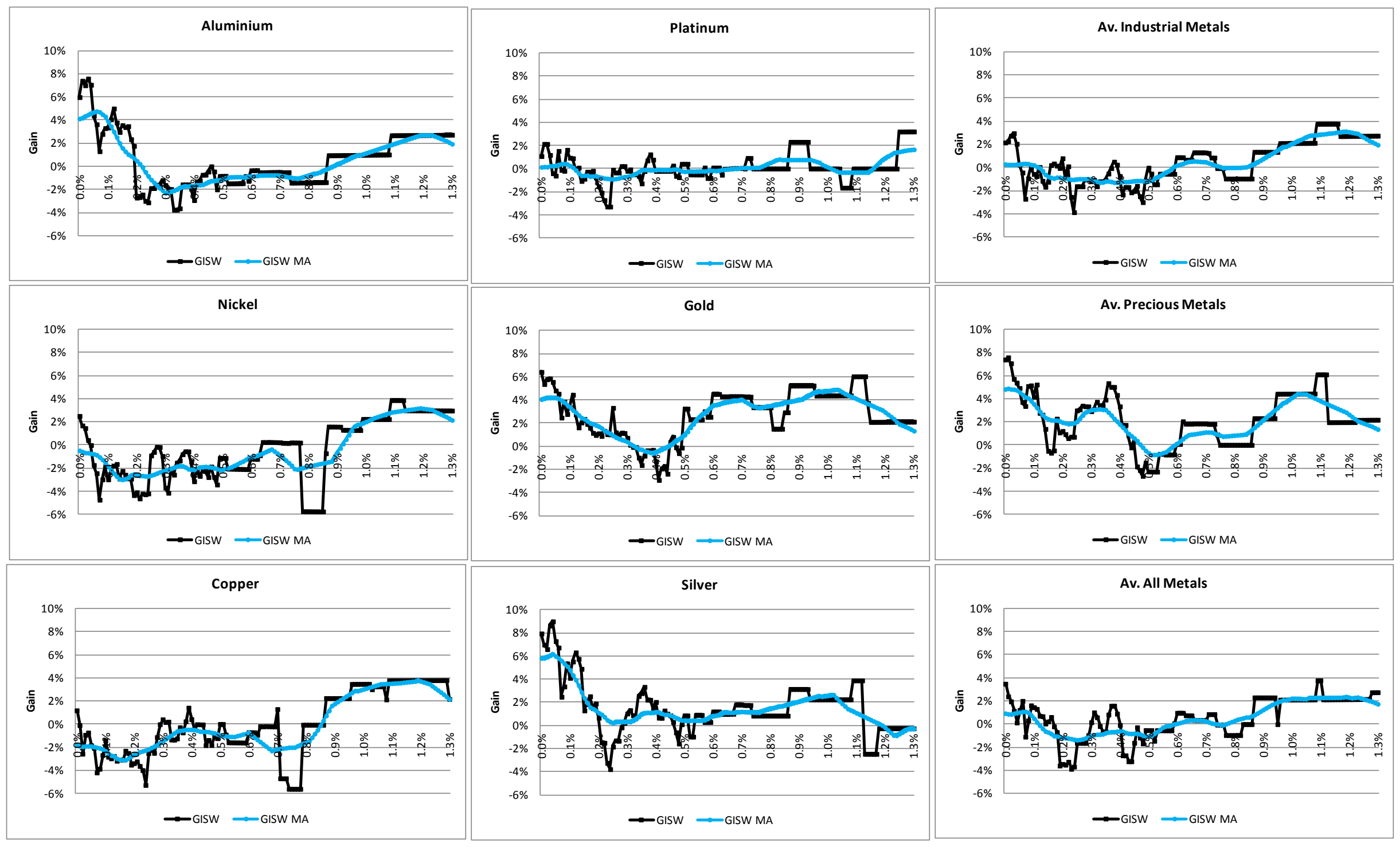




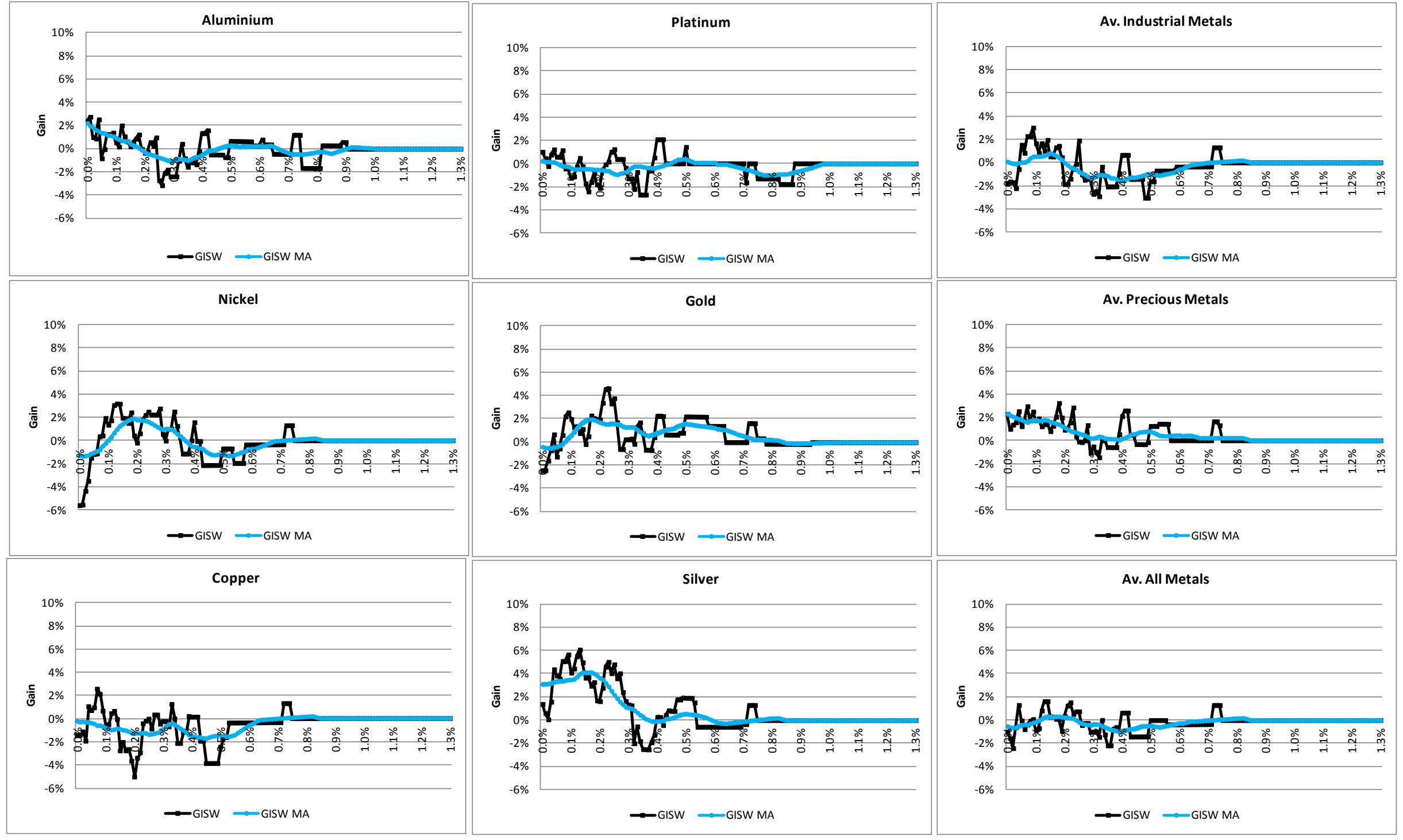




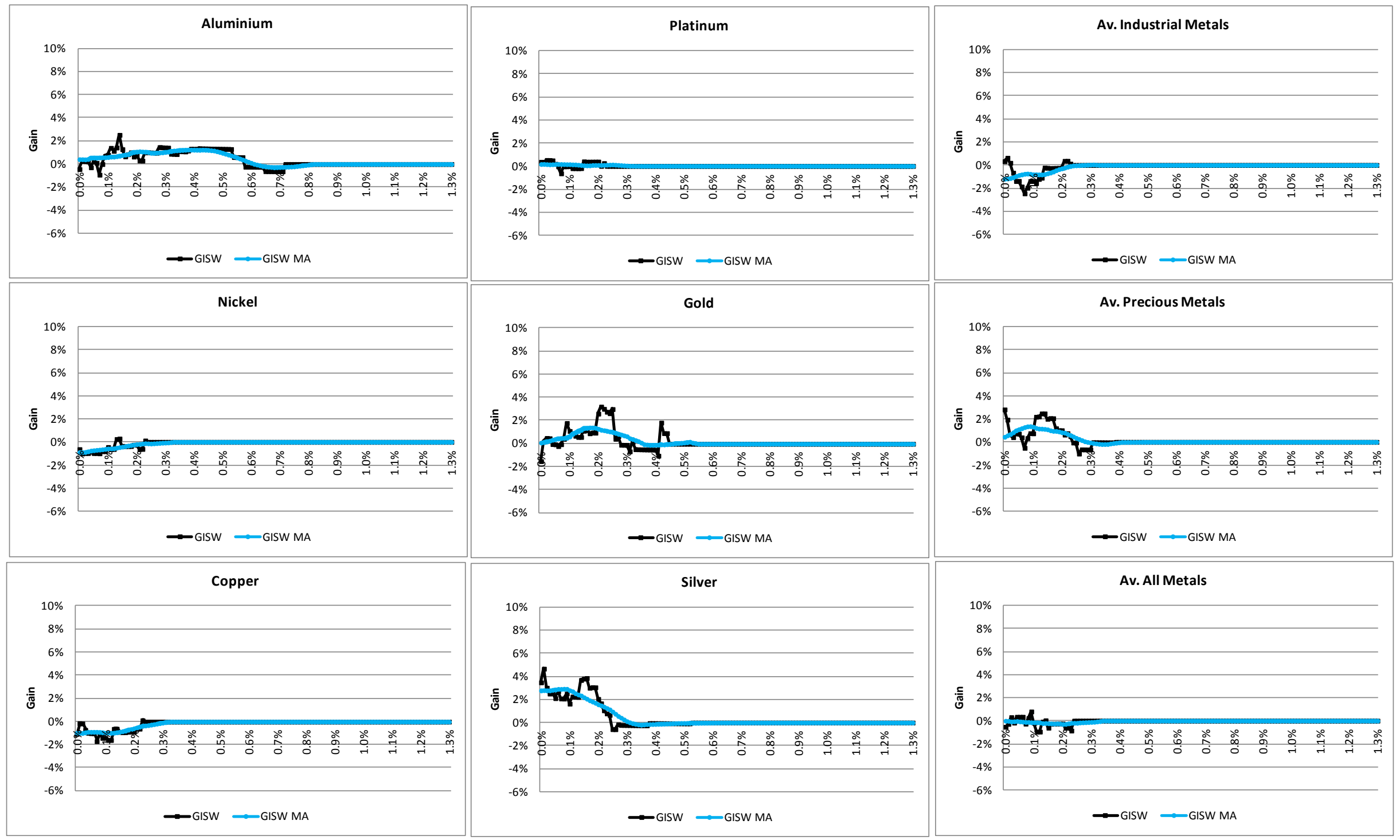




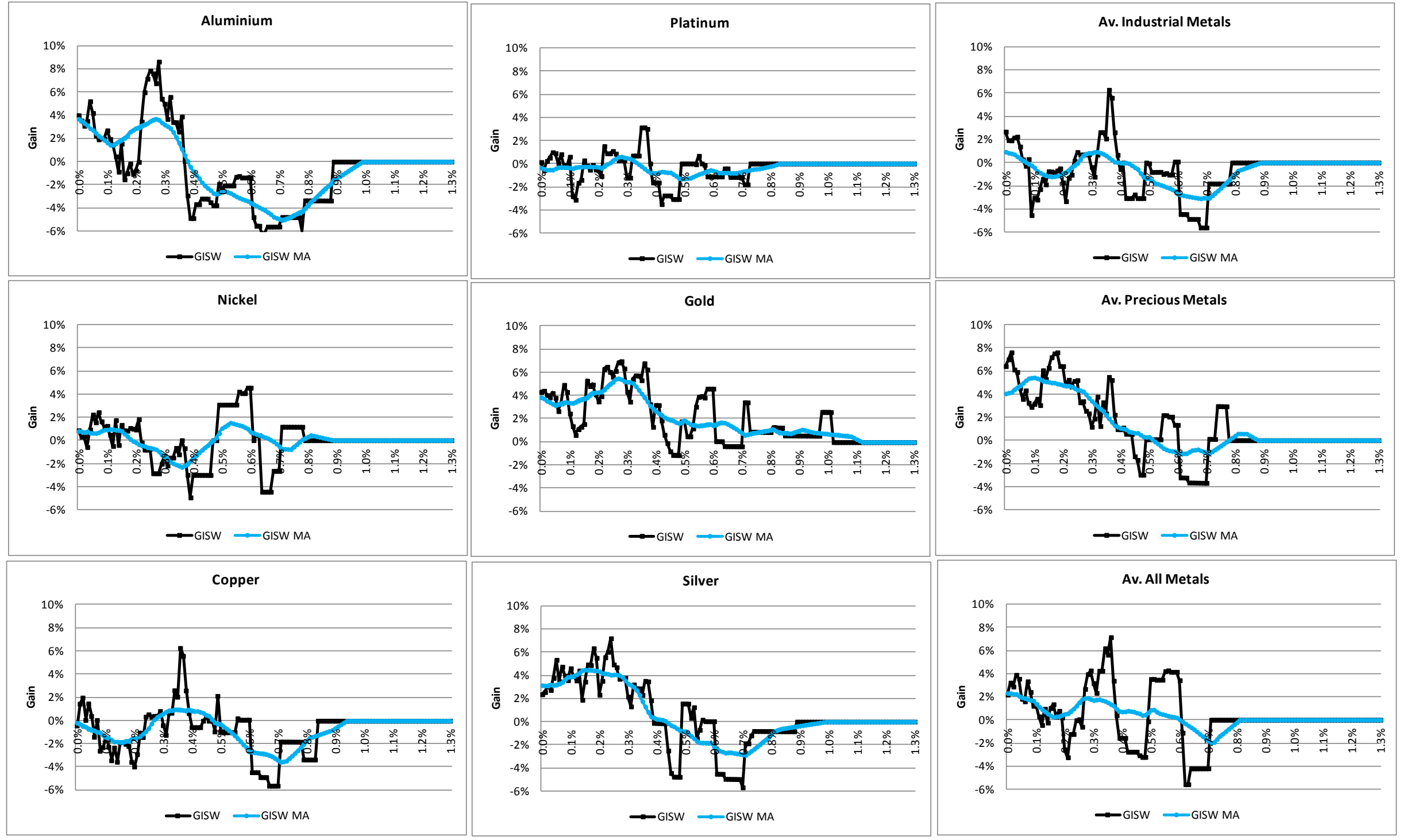




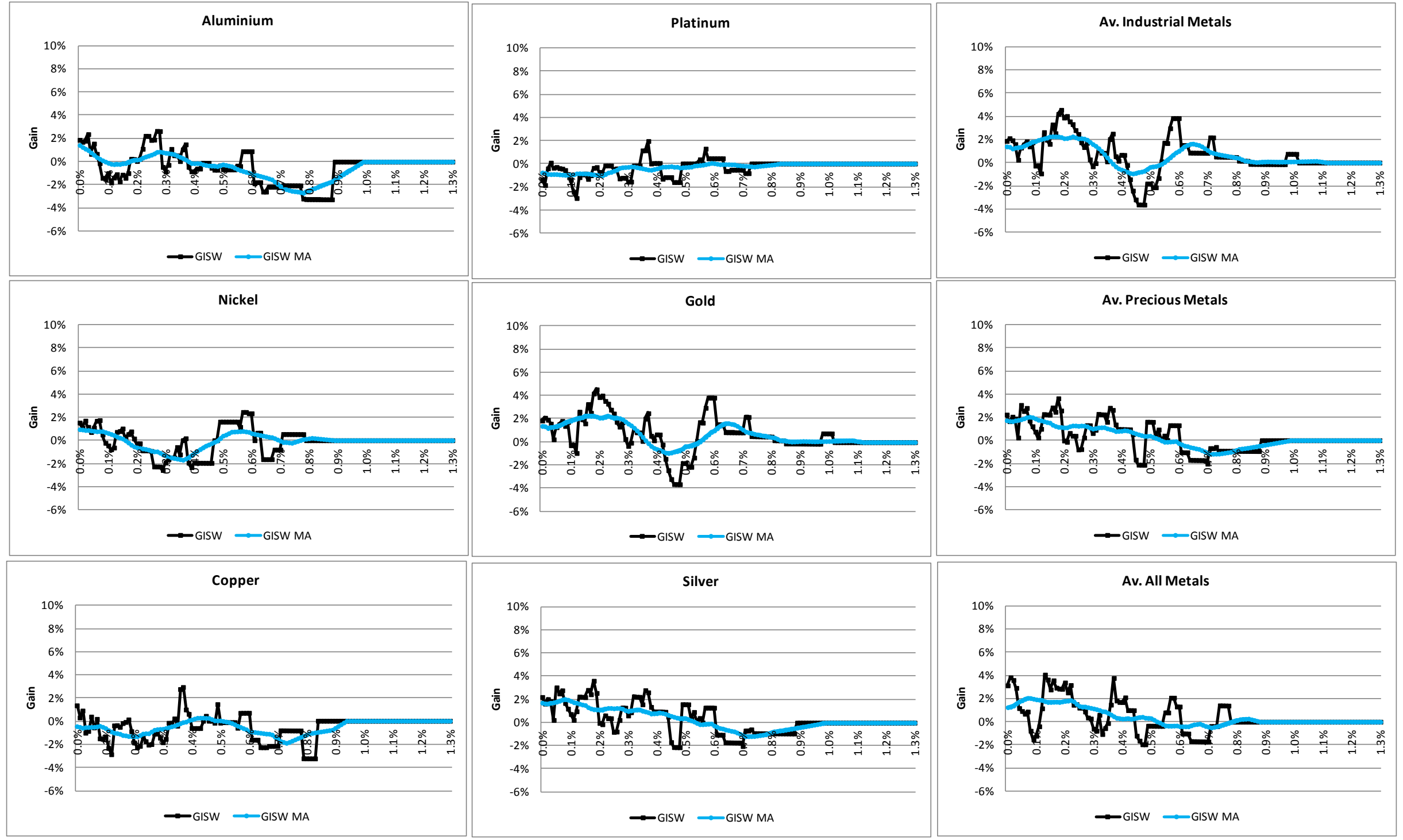


Panel F: UK

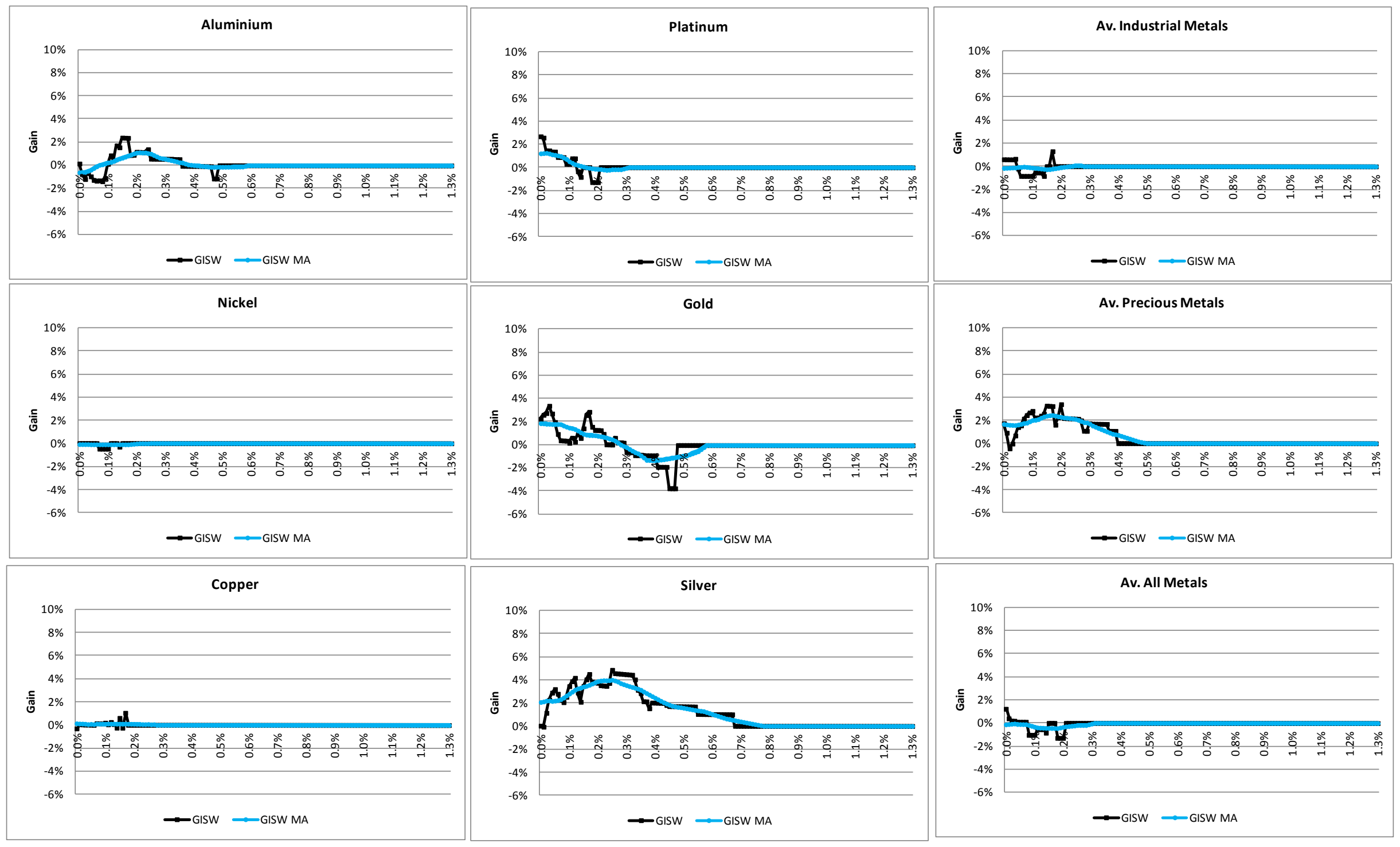




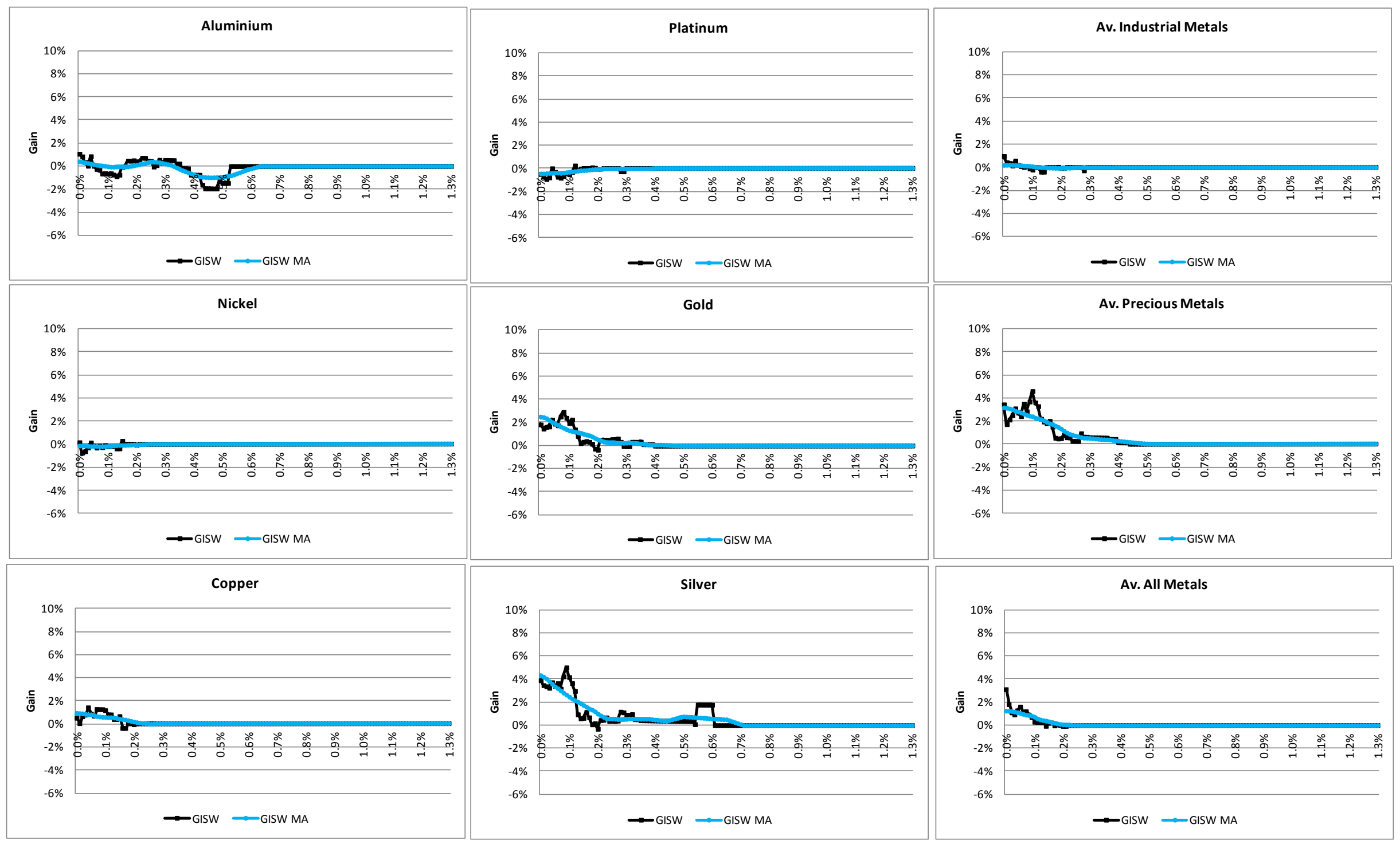

Notes: This figure plots the GISW gain (y-axis) from using the forecasts from commodity returns over the AR(1) benchmark against the level of round-trip trading cost (x-axis). The header for each graph identifies the commodity used. Av.IndustrialMetals is based on forecasts that use an average of the industrial metals. Av. PreciousMetals is based on forecasts that use an average of the Silver and Gold forecasts. Av.AllMetals is based on forecasts that use an average of all metals, both precious metals and industrial metals. The darker line is the point GISW estimate and the lighter line is the 21 point moving average of GISW (GISW MA). 